\title{
„Die ersten werden die letzten sein“ und „Die Frau soll in der Ver- sammlung schweigen“. Direkte Demokratie und Frauenstimmrecht
}

\section{Nadja Braun Binder/Hans-Urs Wili-Luginbühl*}

Was waren das für schöne Zeiten!

In Ecclesia mulier taceat! ${ }^{1}$
Du willst dich freventlich emanzipieren

Und aufstehn wider mich mit keckem Sinn,

Für überaus wichtige und hilfreiche kritische Hinweise danken wir dem Mitherausgeber Herrn Privatdozenten Dr. Otmar Jung herzlich.

1 Goethe spielt damit auf 1. Korinther 14,34 an, wo Paulus (?) den Frauen gebietet, in der

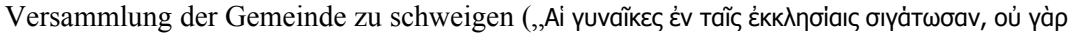

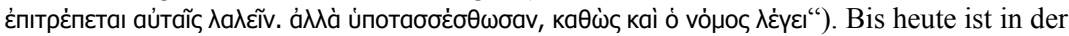
neutestamentlichen Wissenschaft scharf umstritten, ob das Wort echt paulinisch oder nicht ein deutero- oder tritopaulinischer Einschub aus der „Verbürgerlichung“ der Kirche in der Zeit der Pastoralbriefe ist. Vgl. statt vieler für sekundäre Interpolation W. Schrage, Der erste Brief an die Korinther (1 Kor 11,17-14,40; Evangelisch-katholischer Kommentar zum Neuen Testament EKK, VII/3), 1999, S. 479 ff.; H. Conzelmann, Der erste Brief an die Korinther (Meyers Kritisch-exegetischer Kommentar über das Neue Testament KEK, V), 1981, S. 298 f.; paulinische Ursprünglichkeit des Verbots verfechten neben vielen andern E.W. Stegemann/W. Stegemann, Urchristliche Sozialgeschichte. Die Anfänge im Judentum und die Christusgemeinden in der mediterranen Welt, 1995, S. 340 f.; G. Lüdemann, Paulus, der Heidenapostel, Bd. I: Studien zur Chronologie (Forschungen zur Religion und Literatur des Alten und Neuen Testaments 125), 1980, S. 89. Dazu kontrastiert nur scheinbar, dass die Frauen in kirchlichen Wahlangelegenheiten bereits in der Antike Mitentscheidungsrechte gehabt haben sollen: vgl. R. Selinger, Abstimmungen und Wahlen in Athen und Rom, in: L. Carlen (Hrsg.), Forschungen zur Rechtsarchäologie und Rechtlichen Volkskunde, Bd. 20, 2003, S. 35 (47). Diese Zulassung beschränkte sich auf die von den Kaisern (vgl. Lex de imperio Vespasiani, in: Corpus Inscriptionum Latinarum VI 930,10 ff.) geförderte spätrömische Wahlgewohnheit der Akklamationswahl (Tacitus, Annales 1,15: „moderante Tiberio ne plures quam quattuor candidatos commendaret sine repulsa et ambitu designandos“. Quintilianus, Institutio 6,3,62 beschreibt Caesaris candidatus als den Designierten, der seine Wahl auf sicher hat [,Iungitur amphiboliae similitudo, ut a L. Galba, qui pilam neglegenter petenti ,sic' inquit ,petis tamquam Caesaris candidatus'. Nam illud ,petis' ambiguum est, securitas similis. Quod hactenus ostendisse satis est"]; dazu vgl. H. Hausmaninger, Art. Candidatus, in: K. Ziegler/W. Sontheimer/H. Gärtner [Hrsg.], Der Kleine Pauly, Lexikon der Antike, 1979, Bd. I, Sp. 1035 f.), die auf die Bischofswahl übertragen wurde. Von einem Wahlrecht im heutigen Sinne konnte keine Rede sein; genutzt wurde dabei vielmehr der Gruppendruck. Bände über das In ecclesia mulier taceat spricht Ludvig Baron Holbergs (1684-1754) Komödie Jean de France oder Hans Franzen (1722) in fünf Akten im 2. Akt, 3. Szene: 
Jetzt, da eine jegliche Stimme hat, Was will Ecclesia bedeuten.

Was die Weiber lieben und hassen, Das wollen wir ihnen gelten lassen; Wenn sie aber urteilen und meinen, Da will's oft wunderlich erscheinen.

Johann Wolfgang Goethe, Gedichte. Nachlese: Zahme Xenien VII aufs eigne Fäustchen Deine Wirtschaft führen, Du schöne kleine Jakobinerin?

Zur Politik nun auch Dein Wörtlein sagen, Aus trauter Kammer in den Ratsaal fliehn? Wohl gar mit weicher Hand die Trommel schlagen,

wenn einst wir gegen die Tyrannen ziehn?

Berufest Dich auf meine eignen Lehren

Von Freiheit, Gleichheit und von Menschenrecht?

O laß, mein Kind, mit Küssen Dich bekehren, dies eine Mal errietest Du mich schlecht!

Gottfried Keller, in: Stuttgarter Morgenblatt für gebildete Stände Juni $1845^{2}$

\section{A. Einleitung}

Die Schweiz wird (zu Unrecht) verbreitet als Wiege der direkten Demokratie betrachtet. Dies stimmt schon deshalb nicht, weil die Schweiz die (halb-)direkte Demokratie nicht hervor gebracht hat, sondern ihrerseits aus der direkten Demokratie entstanden ist.

Was aber immer wieder irritiert, ist der Umstand, dass in der Schweiz die Frauen das Stimm- und Wahlrecht erst 1971 erhalten haben ${ }^{3}$.

Marthe (Magd): Wär' ich Assessor in einem Collegium mit Dir, so würd' es mir ergehen wie den gescheidten Richtern, die einen Dummkopf zur Seite haben; ich hätte immer über zwei Stimmen zu verfügen.

Espen (Diener): Verstehst Du Latein, Marthe?

Marthe: Gerade so viel wie Du.

Espen: Weißt Du, was das heißt: mulier taceat in ecclesia?

Marthe: Nein, das weiß ich nicht.

Espen: Das heißt auf Dänisch so viel, daß eine solche Sau, wie Du bist, Rocken und Spule wahrnehmen und nicht daran denken soll, sich in Sachen zu mengen, zu denen die Natur mich und andere Mannspersonen geschaffen hat.

Marthe: Das solltest Du nicht sagen, Espen, die Zeit wird noch kommen, wo man mehr auf den Verstand als auf das Geschlecht, mehr auf das Talent als auf den Namen sieht. Wenn unser beider Verstand auf die Wagschaale gelegt wird, und ich dann zum Oberrichter ernannt werde, so kannst Du es nicht höher bringen als zum Apfelhöcker.

(Ludwig Holberg's Ausgewählte Komödien, aus dem Dänischen übertragen von R. Prutz, Erster Theil. [Bibliothek ausländischer Klassiker in deutscher Übersetzung], 1868, S. 83 [102]); vgl. dazu Schrage, ebda., S. 497 Fn. 798.

2 Hier zitiert nach $H$. Mojem, Unvergessene Jugendgedichte. Wie Gottfried Keller sich seiner lyrischen Anfänge erinnerte, in: NZZ 2008 Nr. 149.

3 H.K. Heußner/O. Jung, Die direkte Demokratie in der Schweiz, in: dies. (Hrsg.), Mehr direkte Demokratie wagen. Volksentscheid und Bürgerentscheid. Geschichte, Praxis, Vorschläge, 2. Aufl. 2009, S. 115 (131 f.) verleihen dieser Irritation mit der Zwischentitelfrage Ausdruck: „Das Frauenstimmrecht - ein dunkler Fleck in der Geschichte der schweizerischen direkten Demokratie?" und gelangen bei aller wohlwollenden Würdigung zum Schluss: „Ein ideales (direkt-) demokratisches System darf jedoch keine Privi- 


\begin{tabular}{|c|c|c|c|c|c|c|c|}
\hline \multirow[t]{2}{*}{ Staat } & \multirow[b]{2}{*}{ 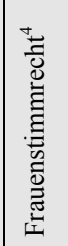 } & \multicolumn{5}{|c|}{ Ereignis } & \multirow[t]{2}{*}{ Bemerkungen } \\
\hline & & 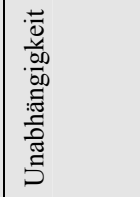 & 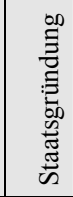 & 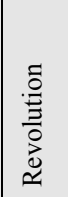 & 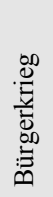 & 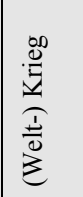 & \\
\hline Neuseeland & 1893 & $1907 / 1931$ & & & & & $\begin{array}{l}\text { Gegner: Alkoholindustrie (Angst vor } \\
\text { Prohibition!) }\end{array}$ \\
\hline Australien & 1902 & $1901 / 1931$ & 1900 & & & & Ballot eingeführt $1855-1879^{5}$ \\
\hline Finnland & 1907 & 1917 & 1906 & & & & \\
\hline Norwegen & 1913 & $1523 / 1905$ & 1905 & & & & $\begin{array}{l}\text { Trennung von Dänemark 1523; } \\
\text { Trennung von Schweden } 1905 \\
\end{array}$ \\
\hline Island & 1915 & 1918 & & & & & $\begin{array}{l}\text { von Dänemark gelöst 1918, Republik } \\
1944\end{array}$ \\
\hline Dänemark & 1915 & 8. Jh./1523 & & & & $\begin{array}{l}1914- \\
1918\end{array}$ & $\begin{array}{l}1523 \text { Trennung von Norwegen und } \\
\text { Schweden; bis } 1918 \text { mit Island; 1940- } \\
1945 \text { unter NS-Herrschaft } \\
\end{array}$ \\
\hline Kanada & 1917 & $1867 / 1931$ & & & & \begin{tabular}{|l|}
$1914-$ \\
1918 \\
\end{tabular} & $\begin{array}{l}\text { Tories: Lohn für Kriegsengagement der } \\
\text { Frauen }\end{array}$ \\
\hline Niederlande & 1917 & 1648 & & & & $\begin{array}{l}1914- \\
1918 \\
\end{array}$ & 1940-1945 unter NS-Herrschaft \\
\hline UdSSR & 1917 & 1917 & & 1917 & & \begin{tabular}{|l|}
$1914-$ \\
1918 \\
\end{tabular} & Vorläufer: russisches Zarenreich \\
\hline Ukraine & 1917 & 1991 & & 1917 & & $\begin{array}{l}1914- \\
1918 \\
\end{array}$ & bis 1991 Teilrepublik der UdSSR \\
\hline Deutschland & 1918 & $\begin{array}{l}843 / 1871 / \\
1933-1945 \\
1949 / 1990\end{array}$ & & & & $\begin{array}{l}1914- \\
1918\end{array}$ & $\begin{array}{l}\text { Vertrag von Verdun 843; Deutsches } \\
\text { Reich 1871; Kaisersturz 1918; Drittes } \\
\text { Reich (NS-Staat 1933-1945); Gründung } \\
\text { der BRD 1949; Beitritt der DDR zur } \\
\text { BRD } 1990\end{array}$ \\
\hline $\begin{array}{l}\text { Groß- } \\
\text { britannien }\end{array}$ & 1918 & 9. Jh. & & & & \begin{tabular}{|l|}
$1914-$ \\
1918 \\
\end{tabular} & \\
\hline Irland & 1918 & $1921 / 1949$ & & 1918 & & $\begin{array}{l}1914- \\
1918\end{array}$ & bis 1921 britisches Dominium \\
\hline Luxemburg & 1918 & $\begin{array}{l}1815 / 1867 / \\
1890\end{array}$ & & & & $\begin{array}{l}1914- \\
1918 \\
\end{array}$ & $\begin{array}{l}1815 \text { Wiener Kongress; } 1867 \text { Londoner } \\
\text { Vertrag bestätigt Unabhängigkeit; } 1890\end{array}$ \\
\hline
\end{tabular}

legien - und keine Benachteiligungen - aufgrund von Geschlecht, Rasse oder ökonomischem Status vorsehen. Das schweizerische politische System hat diese ,Reife“ aus eigener Kraft erst spät erreicht. Schneller hätte es gehen können, wenn eine voll ausgebaute verfassungsgerichtliche Normenkontrolle auf Bundesebene existiert hätte, die alles Recht an unabänderlichen Verfassungsgrundsätzen prüft." Ob dem damit abzuhelfen gewesen wäre, darf aufgrund des Bundesgerichtsentscheids BGE 83 I 173 freilich bezweifelt werden.

4 Vgl. zu dieser Kolonne A. Karam (Hrsg.), Women in Parliament: Beyond Numbers (International IDEA Handbook Series 2), Stockholm 1998, S. 162 f. Tabelle 8.

5 Vgl. N. Braun, Stimmgeheimnis. Eine rechtsvergleichende und rechtshistorische Untersuchung unter Einbezug des geltenden Rechts, 2006, S. 45 ff. Rz. 112 f. 


\begin{tabular}{|c|c|c|c|c|c|c|}
\hline & & & & & & $\begin{array}{l}\text { Personalunion mit der Krone der Nie- } \\
\text { derlande aufgelöst }\end{array}$ \\
\hline Österreich & 1919 & $\begin{array}{l}1282 / 1867 / \\
1918 / 1945 / \\
1955\end{array}$ & & & $\begin{array}{l}1914- \\
1918\end{array}$ & $\begin{array}{l}\text { Habsburgerreich ab 1282-1805; } 1867 \\
\text { Österreichisch-ungarische Doppelmo- } \\
\text { narchie; 1918-1938 Republik; 1938- } \\
1945 \text { unter NS-Herrschaft; } 1945 \text { Wie- } \\
\text { derherstellung der Republik; } 1955 \\
\text { Staatsvertrag }\end{array}$ \\
\hline $\begin{array}{l}\text { Tschecho- } \\
\text { slowakei }\end{array}$ & 1919 & $\begin{array}{l}1918 / 1945 / \\
1993\end{array}$ & 1918 & & $\begin{array}{l}1914- \\
1918\end{array}$ & $\begin{array}{l}1918 \text { Unabhängigkeit; } 1945 \text { Wiederher- } \\
\text { stellung der Republik; } 1993 \text { Trennung } \\
\text { Tschechien-Slowakei }\end{array}$ \\
\hline Polen & 1919 & 1918 & & & $\begin{array}{l}1914- \\
1918\end{array}$ & \\
\hline USA & 1920 & 1776 & & & \begin{tabular}{|l|}
$1917-$ \\
1918 \\
\end{tabular} & \\
\hline Ungarn & $\begin{array}{l}1920 / \\
1949\end{array}$ & $\begin{array}{l}1000 / 1867 / \\
1918\end{array}$ & 1918 & & $\begin{array}{l}1914- \\
1918 \\
1939- \\
1945\end{array}$ & $\begin{array}{l}1000 \text { Krönung König Stefans I.; } 1867 \\
\text { Österreichisch-ungarische Doppelmo- } \\
\text { narchie; } 1918 \text { Republik }\end{array}$ \\
\hline Schweden & 1921 & $1523 / 1905$ & 1905 & & \begin{tabular}{|l|}
$1914-$ \\
1918 \\
\end{tabular} & \begin{tabular}{|l}
1523 Trennung von Dänemark; 1905 \\
Trennung von Norwegen
\end{tabular} \\
\hline Mongolei & 1924 & 1921 & & 1918 & & $\begin{array}{l}1946 \text { Unabhängigkeit von China aner- } \\
\text { kannt }\end{array}$ \\
\hline Ecuador & 1929 & $1809 / 1830$ & & & & $\begin{array}{l}1809 \text { Unabhängigkeit von Spanien; } \\
1830 \text { Loslösung aus Großkolumbien }\end{array}$ \\
\hline Sri Lanka & 1931 & 1948 & & & & bis 1948 britische Kolonie \\
\hline Thailand & 1932 & 1782 & & & & 1782 Königreich Thailand \\
\hline Uruguay & 1932 & 1828 & & & & bis 1828 spanische Kolonie \\
\hline Kuba & 1934 & 1902 & & & & $\begin{array}{l}\text { bis } 1902 \text { spanische Kolonie; US-Inter- } \\
\text { ventionen } 1898,1903,1906-1909,1912, \\
1917-1922+1940\end{array}$ \\
\hline Türkei & 1934 & 1923 & 1923 & & $\begin{array}{l}914- \\
1922 \\
\end{array}$ & $\begin{array}{l}1923 \text { Republik; Reformen Mustafa Ke- } \\
\text { mal Atatürks }\end{array}$ \\
\hline Indien & 1935 & 1947 & & & & bis 1947 britisch \\
\hline Philippinen & 1937 & 1948 & & & & $\begin{array}{l}\text { bis } 1898 \text { spanisch; } 1898-1902 \text { US-Inter- } \\
\text { vention; daraufhin bis } 1946 \text { US- } \\
\text { Dominium }\end{array}$ \\
\hline $\begin{array}{l}\text { Dominika- } \\
\text { nische Re- } \\
\text { publik }\end{array}$ & 1942 & 1863 & & & & $\begin{array}{l}\text { bis } 1844 \text { spanisch; US-Interventionen } \\
\text { 1903, 1904, 1907, 1914, 1916-1924 + } \\
\text { 1930 (Diktatur Trujillo) }\end{array}$ \\
\hline Frankreich & 1944 & $\begin{array}{l}843 \\
1940-1945\end{array}$ & & & $\begin{array}{l}1939- \\
1945\end{array}$ & $\begin{array}{l}843 \text { Vertrag von Verdun; 1940-1945 } \\
\text { vom NS-Staat besetzt; } 1945 \text { Wiederher- } \\
\text { stellung der Republik }\end{array}$ \\
\hline Italien & 1945 & $\begin{array}{l}1861 / 1870 \\
1945\end{array}$ & & & $\begin{array}{l}1939- \\
1945\end{array}$ & $\begin{array}{l}1861 \text { italienische Einigung; } 1870 \text { An- } \\
\text { schluss des Kirchenstaates inkl. Roms; } \\
1922-1945 \text { faschistische Diktatur; } 1947 \\
\text { Republik }\end{array}$ \\
\hline Liberia & 1945 & 1847 & & & & $\begin{array}{l}1847 \text { Staatsgründung durch repatriierte } \\
\text { US-Sklaven }\end{array}$ \\
\hline Albanien & 1946 & $\begin{array}{l}1912 \\
1944 \\
1990 \\
\end{array}$ & & & $\begin{array}{l}1939- \\
1945\end{array}$ & $\begin{array}{l}1912 \text { Unabhängigkeit; } 1944 \text { Befreiung } \\
\text { von italienischer Besatzung; } 1990 \text { Fall } \\
\text { der kommunistischen Diktatur }\end{array}$ \\
\hline Japan & 1946 & $\begin{array}{l}660 \text { v. Chr. } \\
1945\end{array}$ & & & $\begin{array}{l}1940- \\
1945\end{array}$ & $\begin{array}{l}1945 \text { Verlust des II. Weltkriegs und } \\
\text { Sturz der Militärdiktatur }\end{array}$ \\
\hline Jugoslawien & 1946 & $1918 /$ & 1946 & & 1941- & 1990-2005 Zerfall in sechs Staaten \\
\hline
\end{tabular}




\begin{tabular}{|c|c|c|c|c|c|c|c|}
\hline & & 1945 & & & & 1945 & \\
\hline Rumänien & 1946 & $\begin{array}{l}1878 / \\
1945 / \\
1990\end{array}$ & & & & $\begin{array}{l}1941- \\
1945\end{array}$ & $\begin{array}{l}1878 \text { (Berliner Kongress) Türkei er- } \\
\text { kennt Unabhängigkeit Rumäniens an; } \\
1945 \text { Befreiung von Besetzung durch } \\
\text { NS-Staat; } 1989 \text { kommunistische Dikta- } \\
\text { tur gestürzt }\end{array}$ \\
\hline El Salvador & 1946 & $1821 / 1839$ & & & & & $\begin{array}{l}\text { bis } 1821 \text { spanische Kolonie; } 1839 \text { Her- } \\
\text { auslösung aus Großkolumbien }\end{array}$ \\
\hline Panama & 1946 & $1821 / 1903$ & & & & & $\begin{array}{l}\text { bis } 1821 \text { spanische Kolonie; } 1903 \text { Los- } \\
\text { lösung aus der Republik Großkolumbi- } \\
\text { en; US-Interventionen 1903, 1904, } \\
\text { 1905, 1908, 1912, 1918, 1921, 1924, } \\
\text { 1925, 1928, 1931, 1932, 1952 + 1955 }\end{array}$ \\
\hline Südafrika & 1946 & $1910 / 1931$ & & & & & bis 1910 britisch \\
\hline Argentinien & 1947 & 1816 & & & & & bis 1816 spanische Kolonie \\
\hline Bulgarien & 1947 & 1908 & & & & $\begin{array}{l}1939- \\
1945 \\
\end{array}$ & $\begin{array}{l}\text { bis } 1878 / 1908 \text { Teil des osmanischen } \\
\text { Reiches }\end{array}$ \\
\hline China & 1947 & $\begin{array}{l}1912 \\
1949\end{array}$ & & & $\begin{array}{l}1947- \\
1951\end{array}$ & & $\begin{array}{l}1912 \text { Ausrufung der Republik; zuvor } \\
\text { Monarchie; } 1949 \text { Ausrufung der Volks- } \\
\text { republik durch Mao Tse Tung }\end{array}$ \\
\hline Myanmar & 1947 & 1948 & & & & $\begin{array}{l}1939- \\
1945\end{array}$ & bis 1948 Teil Britisch-Indiens \\
\hline Venezuela & 1947 & $\begin{array}{l}1811 / 1821 / \\
1830\end{array}$ & & & & & $\begin{array}{l}\text { bis } 1811 \text { spanische Kolonie; Unabhän- } \\
\text { gigkeitserklärung; } 1821 \text { endgültige Un- } \\
\text { abhängigkeit erfochten; } 1830 \text { Loslösung } \\
\text { aus Großkolumbien }\end{array}$ \\
\hline Belgien & 1948 & 1830 & & & & $\begin{array}{l}1940- \\
1945 \\
\end{array}$ & bis 1830 französisch \\
\hline Israel & 1948 & 1948 & 1948 & & & $\begin{array}{l}1948- \\
1949\end{array}$ & \\
\hline Korea & 1948 & 1948 & & & & $\begin{array}{l}1939- \\
1945 \\
\end{array}$ & 1950-1953 Krieg + Staatsteilung \\
\hline Chile & 1949 & 1818 & & & & & bis 1818 spanische Kolonie \\
\hline Costa Rica & 1949 & $1821 / 1838$ & & & & & $\begin{array}{l}\text { bis } 1821 \text { spanische Kolonie; } 1838 \text { Aus- } \\
\text { tritt aus der Zentralamerikanischen Kon- } \\
\text { föderation; } 1921 \text { US-Intervention }\end{array}$ \\
\hline $\begin{array}{l}\text { Griechen- } \\
\text { land }\end{array}$ & 1952 & $1822 / 1830$ & & & $\begin{array}{l}1947- \\
1951 \\
\end{array}$ & & $\begin{array}{l}\text { bis } 1822 \text { türkisch; } 1830 \text { Londoner Pro- } \\
\text { tokoll nach der Schlacht bei Sfakteria }\end{array}$ \\
\hline Schweiz & 1971 & 1648 & 1848 & & 1847 & $\begin{array}{l}1798- \\
1813 \\
\end{array}$ & 1798-1813 französisch besetzt \\
\hline Spanien & $\begin{array}{l}1867 \\
1931 \\
1976\end{array}$ & 1479 & & & & & $\begin{array}{l}1479 \text { Zusammenschluss von Kastilien } \\
\text { und Aragon; kurze liberale Revolution } \\
\text { 1867; dann Gegenputsch; } 1923 \text { Diktatur } \\
\text { Miguel Primo de Rivera y Orbanejas; } \\
\text { 1976 Tod des Diktators Francisco } \\
\text { Franco Bahamonde }\end{array}$ \\
\hline Summe & 52 & & 9 & 4 & 3 & 28 & \\
\hline
\end{tabular}

Es fällt auf, dass sich die Schweiz mit der Einführung des Frauenstimmrechts spezifisch schwer getan hat. Ist diese späte Ausdehnung direkter Demokratie auf die Frauen nicht ein Widerspruch in sich? Logisch sehr wohl, historisch keineswegs. $\mathrm{Zu}$ rechtfertigen ist der späte Einbezug der Frauen in die direkte Demokratie nicht. Aber zu erklären. 
Dies geschieht einerseits mit Blick auf historische Beispiele demokratischer Inklusion (B.) und andererseits dadurch, dass die Einführung des Frauenstimmrechts in Relation gesetzt wird zu anderen Faktoren, nämlich dem Sklavereiverbot, soweit möglich der Judenemanzipation und im Sinne einer Anregung zu vertiefter Forschung zu Religionen bzw. Konfessionen (C.). Schließlich werden die gewonnenen Erkenntnisse mit den gängigen Erklärungsansätzen verglichen (D.) und ein Fazit in Thesenform gezogen (E.).

\section{B. „Direkte Demokratie“}

Direkte Demokratie ist heute weltweit auf dem Vormarsch, oftmals freilich eher propagandistisch denn real $^{6}$. Staaten mit ausgebauten direktdemokratischen Rechten - und dazu gehört die Schweiz - gelten als beneidenswert. Unausgesprochen gilt diese Staatsform heute vielen als erstrebenswertes Ideal, als Inbegriff durchgehender Gleichberechtigung und umfassender Mitbestimmung aller volljährigen Staatsbürgerinnen und -bürger hinsichtlich aller Erlasse, denen sie sich später zu unterziehen haben.

Dieses Bild stimmt nicht, weder politisch noch historisch. Entgegen der Begriffsbildung wurde direkte Demokratie weder mit der Absicht der Gleichberechtigung eingeführt, noch hat sie ihrerseits das Bewusstsein für Gleichberechtigung rascher oder umfassender geschärft. Auch direkte Demokratie muss immer von den Rechtlosen errungen werden. Selbst im Bereich der Sachentscheide wurden Privilegierte kaum je von sich aus der Diskriminierung ihrer komplementären Partnerinnen und Partner gewahr. Einige Blitzlichter auf die Geschichte mögen dies veranschaulichen.

\section{Antike: Bürgerrecht, Sklaven, Frauen und Krieg im alten Athen}

Die Athener Stadtdemokratie hat in ihrem Endstadium bis zur Losdemokratie geführt ${ }^{7}$. Bezeichnenderweise wurde damit die Tyrannei der Dreißig abgelöst ${ }^{8}$,

6 Vgl. H.-U. Wili, Les systèmes d'institutions de démocratie directe dans le monde, in: $F$. Hamon, Le référendum. Documents réunis et commentés (La documentation française. Droit constitutionnel et institutions politiques. Documents d'études $n^{\circ} 1.21$ ), Paris 2007, S. 9 f.; ders., Volksrechte in den Staaten der Welt, in: LeGes spezial 1, 1997, S. 11 ff.; $B$. Kaufmann $/ G$. Kreis/A. Gross, Direkte Demokratie und europäische Integration. Die Handlungsspielräume der Schweiz. (Basler Schriften zur europäischen Integration 75), 2005, S. 21 und v.a. die Webseite www.c2d.ch.

$7 \quad$ Aristoteles, Athenaion Politeia 41 ff., speziell 54 f., 59, 63, 66 und 67.

8 Aristoteles, Athenaion Politeia $35 \mathrm{ff}$. 
die nach dem desaströsen Verlust des Peloponnesischen Krieges (427-404 v. Chr.) und damit dem Untergang der Vorherrschaft Athens errichtet worden war. Zuvor hatten die Athener unter Perikles ihre Blütezeit mit regelmäßigen direktdemokratischen Sachentscheiden begangen? .

Dieses idealisierte Bild bedarf deutlicher Korrekturen. Über weite Strecken ging im alten Athen der „Vormarsch von Freiheit und Sklaverei Hand in Hand“"10. In der zweiten Phase (Sommer 413 v. Chr.) des Peloponnesischen Krieges entliefen 20.000 athenische Sklaven, insbesondere jene aus den Bergwerken $^{11} .70$ Jahre später besaß beispielsweise der Vater des großen Athener Redners Demosthenes eine Waffenfabrik mit 32 Sklaven und eine Möbelwerkstatt mit 20 weiteren ${ }^{12}$. Demosthenes selber, der große Gegner des Makedonenkönigs Philipp II., wurde als Behördenmitglied vom Rat der Athener, der Bouג $\eta$, nach Filibustern ,hinausgeblättert“, d.h. auf Olivenblättern notiert abgewählt ${ }^{13}$. Lysias besaß nach eigenem Ausweis mit seinem Bruder zusammen 120 Sklaven $^{14}$. Für Attika wird die Anzahl der Sklaven Ende des 5. Jahrhunderts v. Chr. auf 60.000-80.000 veranschlagt. Nach der Zeit Alexanders des Großen (d.h. ab 323 v. Chr.) nahm die Anzahl der Sklaven durch Piraterie, neue Handels- und Absatzgebiete und Sklavenaufzucht deutlich $\mathrm{zu}^{15}$. Dennoch: Die neuere Forschung nimmt für griechische Städte eine Sklavenquote von lediglich 15-30 Prozent $\mathrm{an}^{16}$. Die meisten Sklaven waren Nichtgriechen (v.a. Thraker von der

9 Aristoteles, Athenaion Politeia $27 \mathrm{f}$.

10 M. Finley, Was Greek Civilization Based on Slave Labour?, in: ders. (Hrsg.), Slavery in classical antiquity. Views and controversies, 2. Aufl. Cambridge/New York 1968, S. 53 (72: ,the advance, hand in hand, of freedom and slavery“).

11 Thukydides, Der Peloponnesische Krieg VII. Buch, Kap. 27 Vers 5: „Das ganze Land war ihnen (den Athenern) verloren, mehr als 20.000 Sklaven waren schon übergelaufen“ =

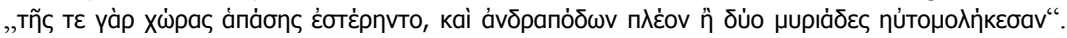
Mühlen und Bergwerke waren die verhasstesten Endstationen antiker Sklavenkarrieren: E. Flaig, Weltgeschichte der Sklaverei, 2009, S. 46.

12 Flaig, Sklaverei (Fn. 11), S. 45.

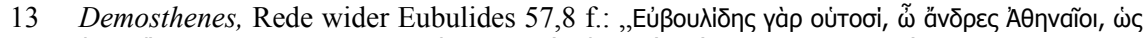

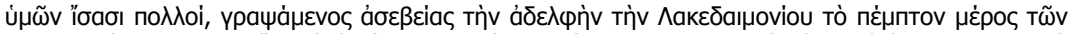

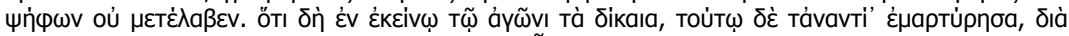

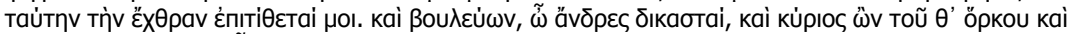

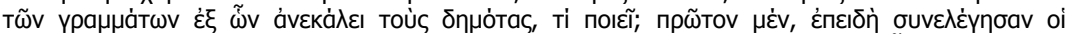

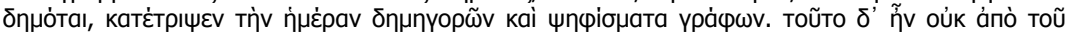

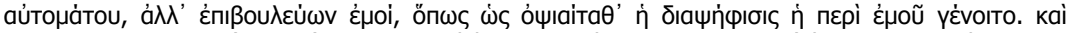

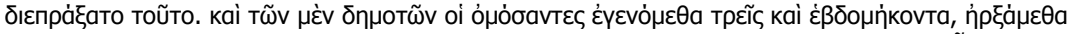

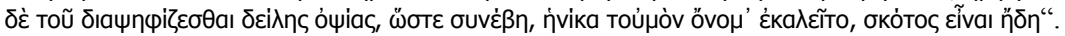

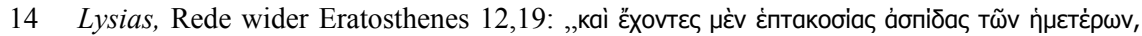

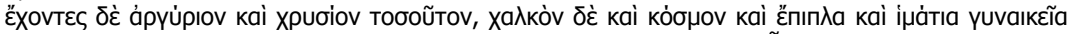

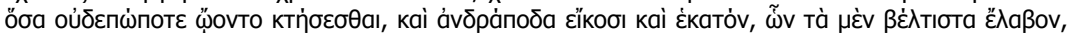

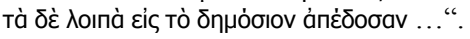

15 H. Volkmann, Art. Sklaverei, in: Ziegler/Sontheimer/Gärtner, Lexikon (Fn. 1), Bd. IV, Sp. 230 (231 f.).

16 Flaig, Sklaverei (Fn. 11), S. 49. 
Schwarzmeerküste und kleinasiatische Karer $)^{17}$. Im alten Athen besuchten mehrere Tausend Bürger an mindestens 40 Tagen die Volksversammlungen und saßen an etwa 150 Tagen in Gerichtshöfen; manche weiteren Ausschüsse tagten überdies sonst noch regelmäßig. Sklaven übernahmen ihre gesellschaftlich notwendige Arbeit ${ }^{18}$. Die Rechtsstellung der Sklaven unterschied sich daher von jener der Freien in nichts ${ }^{19}$ derart klar wie im Bürger- und damit im Stimmrecht: „Der Bürger nämlich wird schlechterdings durch nichts anderes besser definiert

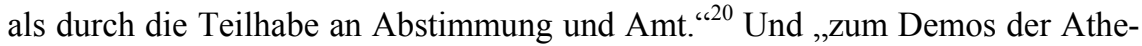
ner, wie er im Protokoll der Volksbeschlüsse entgegentritt, gehörten Metöken ebensowenig wie Frauen. ${ }^{\text {‘21 }}$ Ist es Zufall, dass Aristoteles just im großen Abschnitt über die Sklaverei (1252a 31-1255b 40) seiner Politik auch das Verhältnis zwischen Weiblichem und Männlichem umschreibt? Er meint: „Ferner aber ist die Beziehung des Männlichen zum Weiblichen von Natur aus so, dass das erstere das bessere ist, das letztere aber das schlechtere, das eine das Herrschende und das andere das Beherrschte. Auf dieselbe Art und Weise nun muss

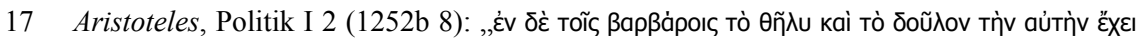

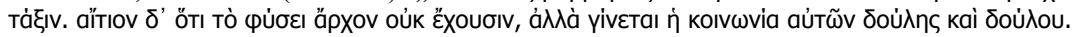

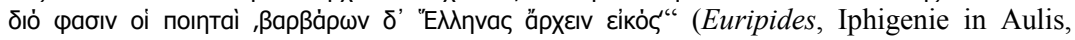
1400).

18 Flaig, Sklaverei (Fn. 11), S. 50. Dieser Befund wird bestätigt durch Platon und Aristoteles, die gegen die sophistische Theorie des Alkidamas von der natürlichen Freiheit aller Menschen die Sklaverei als unerlässlich verteidigen: vgl. Platon, Nomoi VII, 806d/e: „тіఢ

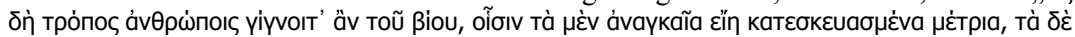

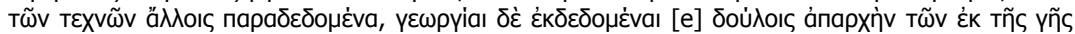

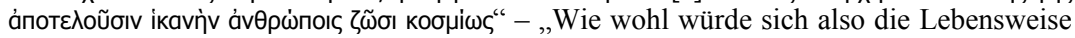
von Menschen gestalten, bei denen ausreichend für das Notwendige gesorgt, die handwerkliche Arbeit andern übertragen und der Ackerbau Sklaven delegiert wäre ..."; außer-

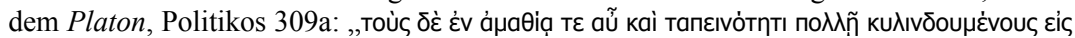

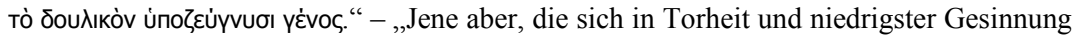
herumwälzen, unterjocht sie ins Sklavengeschlecht"; Aristoteles, Politik I 3 (1253b 34

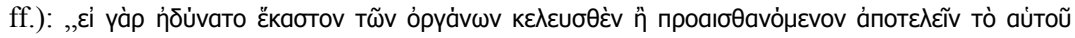

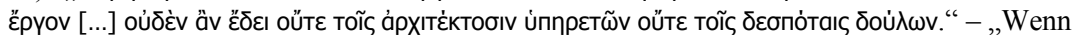
jedes Werkzeug auf Befehl oder den Befehl antizipierend seine Verrichtung wahrnehmen könnte [...], dann allerdings brauchten die Meister keine Gesellen und die Herren keine Sklaven".

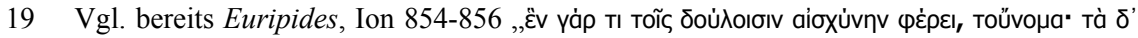

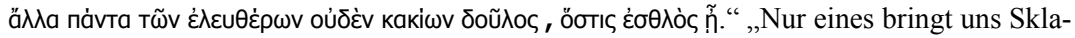
ven Schande ein: Der Name. Hat der Sklave edlen Sinn, so steht er allen freien Bürgern gleich.“ Ähnlich als bloßer Einwand bei Aristoteles, Politik I 3 (1253b 20 ff.). - C. Mann, Politische Gleichheit und gesellschaftliche Stratifikation. Die athenische Demokratie aus der Perspektive der Systemtheorie, in: HZ 286 (2008), S. 1 (4).

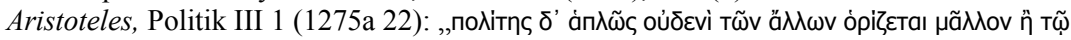

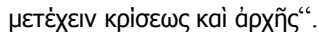

21 Mann, Gleichheit (Fn. 19), S. 4. 
es mit allen Menschen stehen. “22 Und noch eine Beziehung wird von Aristoteles in denselben Gedankenzusammenhang gestellt (1255a 5 f.): „Denn es gibt auch dem Gesetz nach einen Sklaven und einen, der als Sklave dient. Das Gesetz bedeutet nämlich eine Übereinkunft, wonach das im Kriege siegreich Überwundene dem Sieger gehört. “23 Fest steht: Die „Athener waren bei der Vergabe des Bürgerrechts äußerst restriktiv.“24 Außer Frage: „Athenische Frauen waren von eminenter Bedeutung für die Kulte und für die Existenz der oikoi, ohne sie wäre die Demokratie kollabiert. Ebenso hätte die Wirtschaft Athens ohne die Metöken nicht aufrechterhalten werden können, was ebenfalls zum Ende der Demokratie geführt hätte. Aber die Operationen der Demokratie, das heißt des politischen Systems, wurden nicht von Kulten oder dem Austausch materieller Güter bestimmt, sondern gehorchten eigenen Regeln. ${ }^{625}$ Pseudo-Xenophon, aristokratischer Verlierer und scharfer Kritiker der Athener direkten Demokratie zur Zeit des Peloponnesischen Krieges, findet es bezeichnend, dass die Athener in den Städten der Bundesgenossen das einfache Volk unterstützten, denn dieses bleibe dem herrschenden Pöbel Athens eher treu als es die Aristokraten der assoziierten Poleis täten ${ }^{26}$. Diese Argumentation schließt interessanterweise an Herodots Äußerung über die Motivation des Persers Mardonios an, den Ioniern die Demokratie zu bringen: Lähmung der Widerstandsfähigkeit beim unterworfenen politischen Feind durch eine möglichst schwerfällige Staatsform! Damit wird ein weiterer kriegerischer Zusammenhang sichtbar ${ }^{27}$. Herodot ( 484-428 v. Chr.) legt in seinen Historien zuvor dem persischen Edelmann Otanes, dem Sohn des Pharnaspes, Schwager des Kyros und Schwiegervater von Kambyses und Dareios, die „Erfindung“ der Demokratie in den Mund: „Wenn aber die Volksmen-

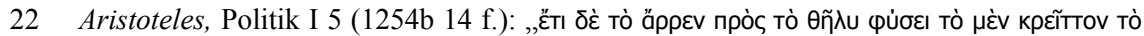

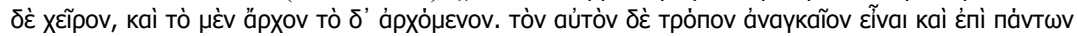

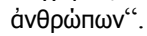

23 Aristoteles, Politik I 6 (1255a 5 f.): „ó үà vó

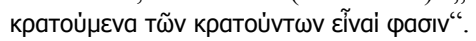

24 Mann, Gleichheit (Fn. 19), S. 4.

25 Mann, Gleichheit (Fn. 19), S. 6.

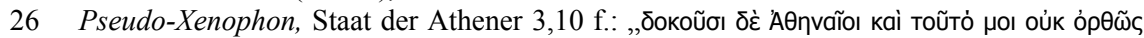

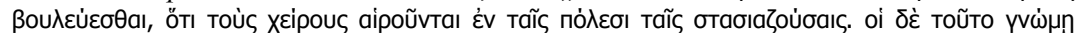
noıõ̃

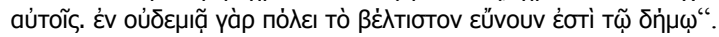

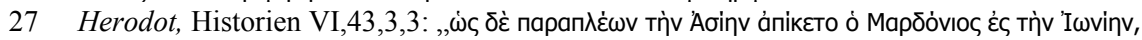

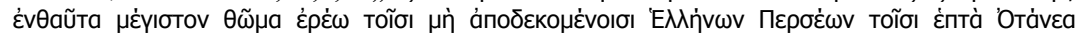

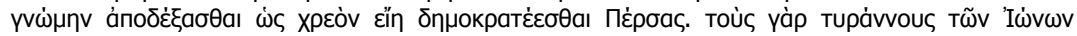

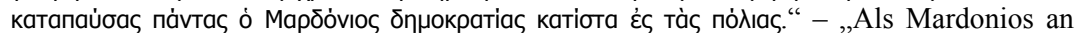
Asien vorbeifuhr und nach Ionien kam, da geschah etwas, was ich zum größten Staunen denen von den Hellenen erzählen will, die nicht glauben, dass Otanes den sieben Persern seine Meinung dahin kundgetan habe, es sei für die Perser eine demokratische Regierungsform erforderlich. Mardonios setzte nämlich alle Tyrannen der Ioner ab und richtete demokratische Verfassungen in den Städten ein.“ 
ge herrscht, so hat diese Staatsform zunächst den allerschönsten Namen, nämlich Isonomie (Rechtsgleichheit). Außerdem tut sie nichts von alledem, was ein Alleinherrscher macht: Sie besetzt die Ämter durch Verlosung, über die Amtsführung fordert sie Rechenschaft, alle Beschlüsse werden der Allgemeinheit vorgelegt. Mein Votum also lautet, dass wir die Alleinherrschaft aufgeben und die Volksmenge an die Macht bringen. Denn bei den vielen liegt alles. “28

Platon hat sich mit dieser Isonomie in zwei philosophischen Dialogen auseinandergesetzt. Im Menexenos rechnet er die Rechtsgleichheit den Athenern zur Ehre an: „Andere Staaten sind aus vielerlei und ungleichen Menschen gebildet, daher auch ihre Verfassungen die Ungleichheit darstellen in willkürlicher Herrschaft eines einzelnen (Tyrannis) oder weniger (Oligarchie). Sie sind daher so eingerichtet, dass einige die anderen für Knechte und diese jene für Herren halten. Wir aber und die unsrigen, von einer Mutter alle als Brüder entsprossen, begehren nicht, Knechte oder Herren einer des anderen zu sein, sondern die natürliche Gleichbürtigkeit nötigt uns, auch Rechtsgleichheit gesetzlich zu suchen und um nichts anderen willen uns einander unterzuordnen als wegen des Rufes der

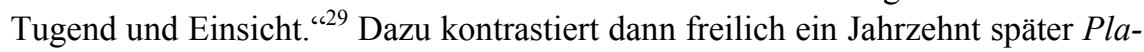
tons Verständnis der Isonomie der Geschlechter in seinem Dialog Politeia: „Das Äußerste jedoch, o Freund, was an Freiheit der Menge in einem solchen Staat zum Vorschein kommt, ist wohl dies, wenn die gekauften Männer und Frauen nicht minder frei sind als ihre Käufer. Wie groß aber zwischen Frauen und Männern und Männern und Frauen die Rechtsgleichheit und Freiheit wird, hätten wir beinahe vergessen zu erwähnen. “30

In der Tat: Der Zusammenhang mit dem Krieg verdient noch weitere Beobachtungen. Der große Komödiendichter Aristophanes hat die Athener Demokratie und ihre merkwürdigen Seiten während des und nach dem Peloponnesischen Krieg insbesondere in zwei Werken - in der Lysistrate und in den Ekklesiazousai (Volksversammlung der Frauen) - scharfzüngig aufs Korn genommen:

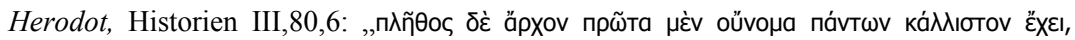

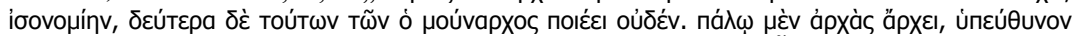

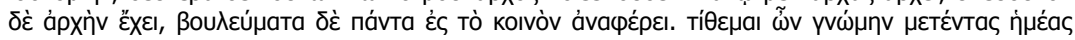

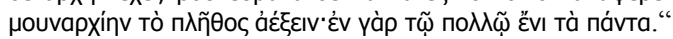

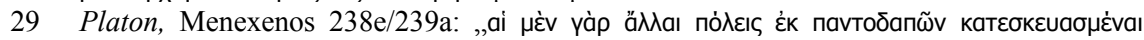

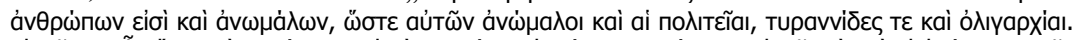

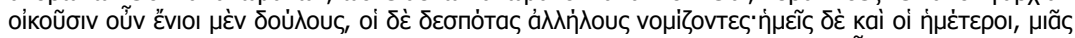

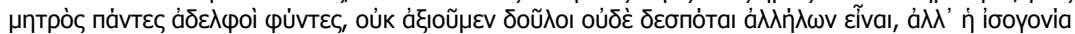

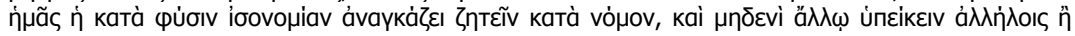

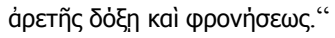

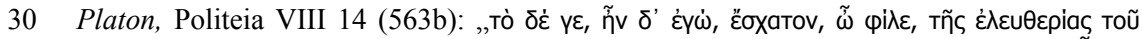

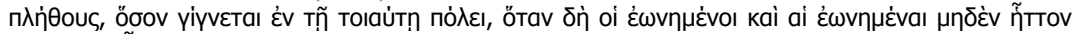

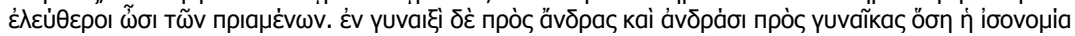

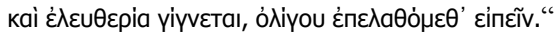


In der Lysistrate (411 v. Chr.) bringt Aristophanes den für Athen bereits weitgehend verlorenen Peloponnesischen Krieg zur Sprache: Mit Liebesverweigerung wollen die Frauen die Männer zu Einsicht und Friedensschluss bringen. Hier interessieren vor allem die Verse 506-520:

Lysistrate: „Wir ertrugen es stets in der vorigen Zeit und im Jammer des Krieges geduldig, sittsamer Natur, wie wir Frauen nun sind, wie Ihr Männer auch immer es triebet. Wir durften nicht mucksen, so hieltet Ihr uns! Und Ihr wart doch gewiss nicht zu loben! Wir durchschauten Euch wohl, und wir ahnten nichts Gutes. Und da kam denn, wenn wir zuhause still saßen, zu Ohren uns oft, wie verkehrt Ihr die wichtigsten Dinge behandelt! Da fragten wir wohl Euch, im Herzen betrübt tief innen, doch lächelnden Mundes: ,Was habt Ihr im Rate des Volks heut früh nun wegen des Friedens beschlossen?‘ [...] Was kümmert das Dich? war die brummende Antwort des Mannes. Ich rate Dir, schweig! [...]

Lysistrate: Und ich schwieg [...] Nicht lange, so hören wir wieder: Ihr habt noch verkehrtere Dinge beschlossen! Und so fragten wir wieder: ,Nein, sage mir, Mann, was macht Ihr für dumme Beschlüsse? ‘ - Da sah er mich an von der Seit' und begann: ,Wenn Du ruhig nicht bleibst bei dem Webstuhl, dann setz' ich zurecht Dir den störrischen Kopf, denn der Krieg ist die Sache der Männer' “،31

Noch einen Schritt weiter geht Aristophanes nach dem Peloponnesischen Krieg 391 v. Chr. in seinem Alterswerk, den Ekklesiazousai: Hier binden sich die Frauen Bärte um und übernehmen unter Anführung der Praxagora die Volksversammlung:

„Um des Agyrrhios willen [...] wollen wir ein so waghalsiges Werk - mehr Demokratie! wagen, die politischen Geschäfte mit unseren Mitteln in die Hand zu nehmen, um so dem Staat etwas Gutes zu tun. Im Augenblick nämlich kommen wir nicht mit Segeln und nicht mit Rudern voran." ${ }^{32}$

31 Übersetzung nach Stegemann/Stegemann, Sozialgeschichte (Fn. 1), S. 341. Originaltext:

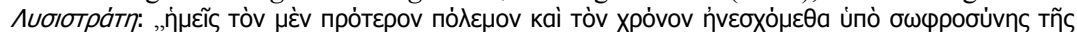

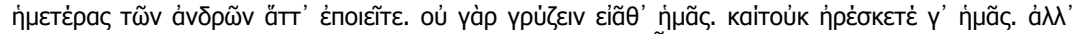

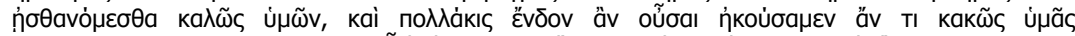

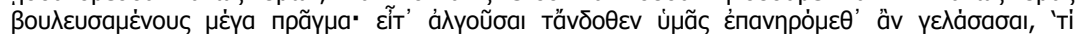

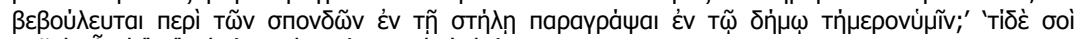

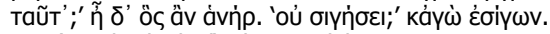

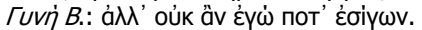

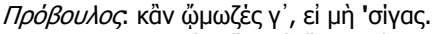

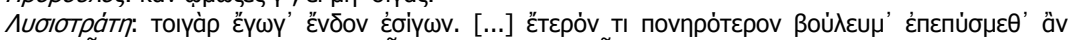

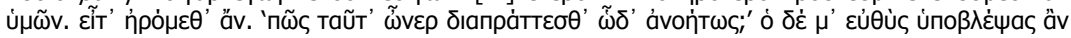

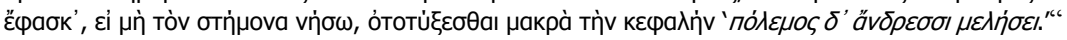

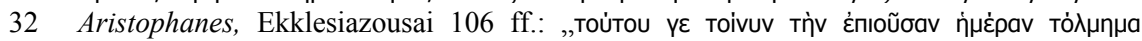

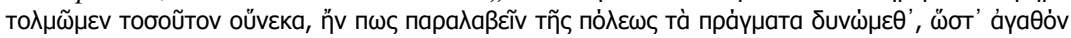

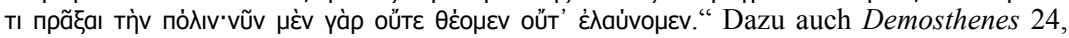
134 f.; Aristoteles, Athenaion Politeia 41,3: Agyrrhios erfand die Diäten, um Unterschichtigen die Teilnahme an der Demokratie zu ermöglichen - gewissermaßen als AntiSteuer; vgl. C. Meier, Wie die Athener ihr Gemeinwesen finanzierten. Die Anfänge der Steuerpolitik in der griechischen Antike, in: U. Schultz (Hrsg.), Mit dem Zehnten fing es an. Eine Kulturgeschichte der Steuer, 1986, S. 25 (32 f., 37). Dazu dann umgekehrt Cas-

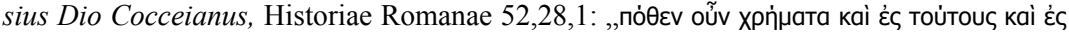

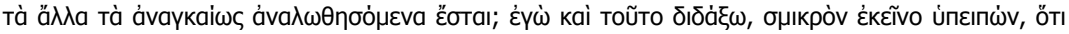


„Ihre (der Männer) Beschlüsse jedenfalls sind - wenn man bedenkt, was sie so alles machen, ganz daneben, wie von Betrunkenen. “33

„... mich bedrückt, was faul in dieser Stadt ist und an ihren Geschäften. Denn ich sehe, dass dieser unser Staat zu Führern immer schlechte Leute nimmt, und wenn einer sich einen einzigen Tag lang brauchbar zeigt, ist er gleich zehn Tage schlecht. Überlässt man aber den Staat dann einem andern, richtet der noch mehr Unheil an. [...] Es gab eine Zeit, da brauchten wir überhaupt keine Volksversammlungen, sondern hielten den Agyrrhios für einen schlechten Mann. Jetzt aber, da der Brauch besteht, preist derjenige, der sein Geld bekommt, ihn (der die Diäten eingeführt hat) überschwänglich ... “34.

„Ihr aber selbst, o Volk, ihr seid an allem schuld! Denn ihr nehmt die öffentlichen Gelder als Lohn mit, und privat seht ihr darauf, was jeder einzelne davon profitieren kann. Das Gemeinwesen dagegen torkelt dahin. [...] Wenn ihr also meinem Rat folgt, dann könnt ihr noch gerettet werden. Den Frauen nämlich, sage ich, müssen wir die Stadt übergeben! ‘35

„Ihnen (den Frauen) also, ihr Männer, wollen wir die Stadt übergeben und nicht darum herum reden und nicht fragen, was sie denn eigentlich tun werden, sondern sie ganz einfach herrschen lassen ..." ${ }^{36}$.

\section{Aristophanes unterstellt den Frauen dann kommunistisches Gedankengut:}

„Sklaven soll nicht der eine haben in Menge, der andere aber nicht einmal einen Begleiter; nein, eine gemeinsame Lebensform schaffe ich, für alle gleich. ${ }^{\text {‘37 }}$

\section{Spätmittelalter und Neuzeit}

Wolf Linder hält generell für die Demokratie fest, „,dass sie kein endgültiges Konzept darstellt. Sie steht in einem ständigen Prozess normativer und faktischer Veränderung, wie die Geschichte der schrittweisen Inklusion von Vermögenslosen, Arbeitern oder Frauen als berechtigte Stimmbürger über den ursprüng-

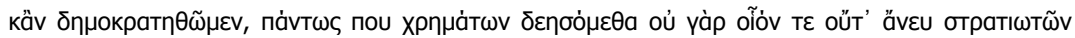

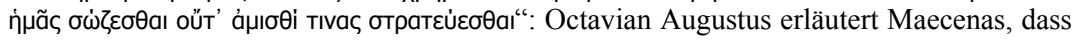
auch Demokratien Steuern erheben müssten, um Soldaten zu entlöhnen.

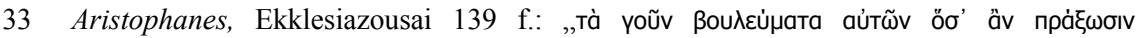

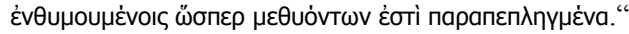

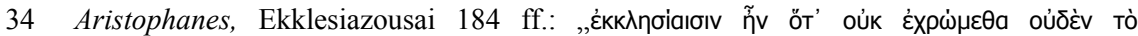

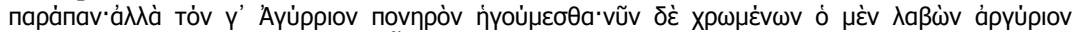

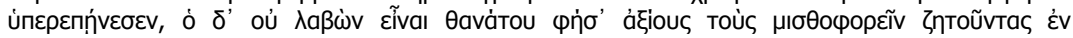

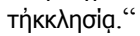

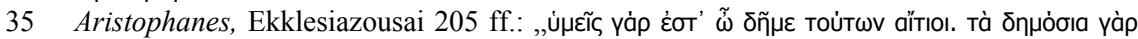

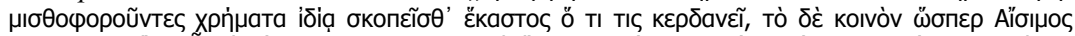

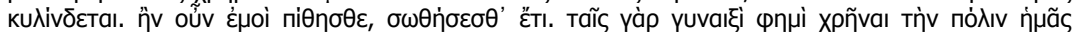
параסоũvaı.“

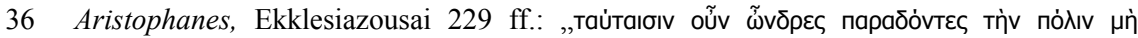

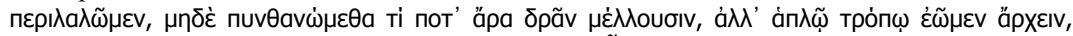

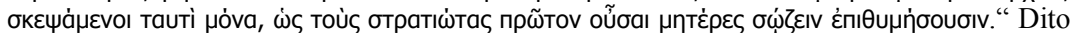
V. $429 \mathrm{f}$ !!

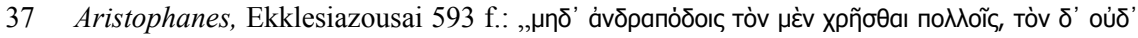

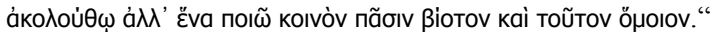


lichen Kreis der männlichen Besitzesbürger hinaus belegt.، ${ }^{\text {38 }} \mathrm{Zu}$ diesen Voraussetzungen scheint in der direkten Demokratie der Eidgenossenschaft für die wirksame Stimmabgabe lange Zeit offenbar auch entweder leibliche Gegenwart in der Landsgemeinde oder aber Alphabetisierung gehört zu haben. Schriftliche Abstimmung kam erst mit der Alphabetisierung in der Volksschulbewegung des 19. Jahrhunderts auf. Und für den physischen Zutritt zur Landsgemeinde bedurfte es nach den Vertreibungen seit der Reformation zur wirksamen Sozialkontrolle eines praktischen und ohne Lesekundigkeit erkennbaren Stimmrechtsausweises.

In jüngerer Zeit hat man aus vereinzelten Dokumenten auf ein einzelfallweises Frauenstimmrecht in bestimmten Orten der alten Eidgenossenschaft schließen wollen $^{39}$. Beim heutigen Kenntnisstand der Quellen lässt es sich zwar nicht mit letzter Sicherheit ausmachen; aber von den einzigen beiden Zeugnissen, die dafür bisher ins Feld geführt wurden, erweckt eines angesichts der gesamten Umstände doch tief greifende Zweifel:

Im Kanton Schwyz sollen 1516 im Anschluss an die desaströse Niederlage der Schweizer in der Schlacht von Marignano 1515 nach einem Bericht des venezianischen Gesandtschaftssekretärs auch Frauen an der Landsgemeinde mitgewirkt haben ${ }^{40}$. Und in der Alpgenossenschaft Saanen wollte man aus einem Landsgemeindebeschluss von 1657 die Konsequenz ableiten, dass zuvor Frauen im Besitz von Alpgenossenrechten an der Landsgemeinde stimmberechtigt gewesen seien. Konsultiert man aber den ganzen Abschnitt des Dokuments, so liegt ein weit „harmloserer“ Rückschluss nahe. Die Urkunde, ein Beschluss der Landsgemeinde der Alpgenossenschaft vom 16. Mai 1657, lautet wörtlich: „Berg mehren halb ein ordnung. Uff dem 25 . Tag meyen des 1657 jahrs ist von gricht und gmein erkent, dass fürthin an gmeinen bärgen keine weibsperson, auch keine mans person, so noch dass $h$. nachtmahl nit empfangen, weder um dess bergs

38 W. Linder, Zur Universalität von Menschenrechten, Markt und Demokratie - zweifelhafte Begründung, fragwürdige Folgen, in: ZfP 57 (2010), S. 207 (210).

39 L. Carlen, Die Landsgemeinde in der Schweiz. Schule der Demokratie, 1976, S. 12 f.; im gleichen Sinn gestützt auf die genau gleichen Quellen ders., Die Landsgemeinde, in: A. Auer (Hrsg.), Die Ursprünge der schweizerischen direkten Demokratie. Actes du Colloque organisé les 27-29 avril 1995 par la Faculté de droit et le C2D, 1996, S. 15 (20); S. Hardmeier, Was uns der Frauenstimmrechtskampf über die ,Erfindung' der Demokratie lehrt, in: Schweizerisches Bundesarchiv (Hrsg.), Die Erfindung der Demokratie in der Schweiz (Studien und Quellen 30), 2004, S. 75 ff. (insb. S. 97 Fn. 9).

40 E. Usteri, Frauen an der Schwyzer Landsgemeinde von 1516, in: NZZ 1972 Nr. 308; ders., Marignano: Die Schicksalsjahre 1515/1516 im Blickfeld der historischen Quellen, 1974, S. 565. Über das Erscheinen von Frau Maria Elisabeth Reding, Gattin des Generals Nazar Reding, im Jahre 1763 an der Schwyzer Landsgemeinde (worüber es auch eine bildliche Darstellung gibt: vgl. die Photographie bei Carlen, Landsgemeinde [Fn. 39], S. 25) W. Keller, Frauen an der Schwyzer Landsgemeinde, in: NZZ 1972 Nr. 453. 
schatzung, noch andre ding zu mehren gwalt haben sölli. Der halben, so jemand theil an einem berg hat und er selbs dahin nit kommen kann, einem andren befehlen mag, an seiner statt zu mehren, doch auch uss einer hausshaltung nicht mehr dan ein person, damit alles ordentlich und unpartheyesch zu gange. ${ }^{\text {“41 }}$ Eher als ein vorbestandenes Frauenstimmrecht legt der Wortlaut nahe, dass der Landsgemeindebeschluss mit einer eingerissenen Praxis brechen wollte, in der sich Stimmberechtigte an der Landsgemeinde durch ihre instruierten Ehefrauen oder durch ihre noch nicht konfirmierten Söhne vertreten ließen. Ein echtes Frauenstimmrecht war damit wohl kaum verbunden; eher könnte eine Absicht, dem vorzubeugen, den Landsgemeindebeschluss provoziert haben.

Zwar mag im Spätmittelalter „die vorherrschende Wirtschaftsform der alpinen Viehhaltung [...], die regelmässig eine längere Abwesenheit vieler Männer von der Heimstätte bedingte“, nahelegen, dass „die Innerschweizer Frauen bei Entscheidungen über Haus und Hof eine gewisse Selbständigkeit genossen haben müssen“42 ; allein, wo (zumeist oberschichtige) Frauen in ,den Urkunden vor allem bei Verkäufen, Schenkungen und sonstigen Besitzwechseln“ auftreten, werden sie doch zumeist (nicht immer) ,in Verbindung mit dem Ehemann oder einem Vormund, der das Rechtsgeschäft vollzieht und besiegelt", genannt. Wenn bei der Besitzveräußerung durch einen Mann die Frau - mit oder ohne Namen erwähnt wird, besteht der Verdacht, es handle sich um Gut, das von der Frau in die Ehe gebracht wurde und nur mit ihrer Einwilligung verkauft werden durfte. Oft aber werden Frauen und Kinder in eine Handänderung mit der Absicht einbezogen, spätere, erbrechtlich begründete Ansprüche auszuschalten. Dies trifft besonders bei Schenkungen an Kirchen und Klöster zu, die nachträglich nicht selten angefochten wurden, namentlich von den erbberechtigten Kindern des Stifters oder vom zweiten Ehemann der Gattin, wenn sich diese nach dem Tod des Stifters wieder verheiratet hatte. ${ }^{\text {“43 }}$

Was bleibt, ist bisher noch ein einziges „... spätmittelalterliches Zeugnis über die rechtliche und gesellschaftliche Stellung der Frau in der Innerschweiz [...]: In der Chronik des Weissen Buchs gibt des Stauffachers Gattin, eine ,kluge Frau', durch ihren Rat das Signal zum Aufstand und damit zur Bundesgründung. Es geht hier gar nicht um die Frage nach der historischen Wirklichkeit der Ereignisse und Personen, aber die Tatsache, dass in einem offiziellen, magistralen Chroniktext, der die Anfänge der Eidgenossenschaft beschreibt, eine Frau ihren

H. Rennefahrt, Die Rechtsquellen des Kantons Bern, Teil II: Rechte der Landschaft, Bd. 3: Das Statutarrecht der Landschaft Saanen (bis 1798), bearbeitet und herausgegeben von H. Rennefahrt, 1942, Nr. 127 (Verschiedene Landsatzungen 1647-1731) Ziff. 52a S. 330 f., abrufbar unter http://www.ssrq-sds-fds.ch/online/BE_II_3/index.html\#p_III (zuletzt besucht am 17.6.2012).

42 W. Meyer, 1291. Die Geschichte. Die Anfänge der Eidgenossenschaft, 1990, S. 67.

43 Meyer, Geschichte (Fn. 42), S. 66. 
eher kleinmütigen Mann zur Tat antreibt, wirft vielleicht doch ein bezeichnendes Licht auf die gesellschaftliche Rolle der Innerschweizer Frauen, die gemäss spätmittelalterlichen Zeugnissen beim Aufruf zur Rache vor Gericht und in der Öffentlichkeit aufzutreten hatten. [...] Bekanntlich rief nach der Hinrichtung des Frischhans Teiling 1487 in Zürich, die von der Innerschweiz als Justizmord empfunden wurde, eine junge Frau, vielleicht die Tochter des Hingerichteten, durch ein Lied die Waldleute zur Rache auf. Diese gesellschaftliche Rolle der Frau mutet, auch wenn die Belege erst im 15. Jahrhundert einsetzen, äusserst urtümlich an und dürfte in frühe Zeiten zurückreichen. “44

Alles in allem scheint es nach kritischer Durchsicht des derzeitigen Forschungsstandes auch in der mittelalterlichen Eidgenossenschaft einschließlich der Reihenfolge doch weit eher bei Wolf Linders Analyse zu bleiben: An der Landsgemeinde teilnahmepflichtig und stimmberechtigt war, wer in Ehr und Wehr $\operatorname{stand}{ }^{45}$, d.h. wehrpflichtige Männer von mindestens 14 bzw. 16 Jahren $^{46}$. Diesbezüglich sind Landsgemeindebeschlüsse wie jener der Talschaft Urseren im Kanton Uri von Interesse, welche ein Verbot statuieren, „die Waffenrüstung (,harnesch') eines im Tale ansässigen Mannes zu pfänden, solange man ein anderes Pfand findet. Das zielt auf die Wehrhaftigkeit und Sicherheit des Tales

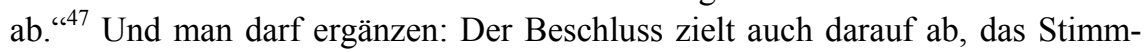
recht an der Landsgemeinde zu erhalten.

44 Meyer, Geschichte (Fn. 42), S. 67.

45 Für Glarus vgl. F. Stucki, Die ,Obrigkeiten“ im alten Land Glarus, 1980, S. 11 ff., 26 f. mit Hinweis auf die zeitweise Stimmberechtigung gewisser Hintersässen, die erst nach der Reformation unterbunden wurde (ebda., S. 12 f.); für Schwyz vgl. B. Adler, Die Entstehung der direkten Demokratie. Das Beispiel der Landsgemeinde Schwyz 1789-1866, 2006, S. 21 f.; generell: E. Osenbrüggen, Studien zur deutschen und schweizerischen Rechtsgeschichte, 1868, S. 117; Carlen, Schule (Fn. 39), S. 12 f.; ders., Landsgemeinde (Fn. 39), S. 20; S. Möckli, Die schweizerischen Landsgemeinde-Demokratien (Staat und Politik 34), 1987, S. 26 f., 31 ff., 41 und 43 f.; H. Ryffel, Die schweizerischen Landsgemeinden, 1903, S. 81; A. Sennhauser, Hauptmann und Führung im Schweizerkrieg des Mittelalters, 1965, S. 50; Amtliches Bulletin der Bundesversammlung (Amtl. Bull.) 1985 Nationalrat, S. 1752; F. Helg, Die schweizerischen Landsgemeinden. Ihre staatsrechtliche Ausgestaltung in den Kantonen Appenzell Ausserrhoden, Appenzell Innerrhoden, Glarus, Nidwalden und Obwalden (Zürcher Studien zum öffentlichen Recht 175), 2007, S. 158 f., 264 und 273.

46 Carlen, Landsgemeinde (Fn. 39), S. 20: „In Uri, Unterwalden und Zug und in verschiedenen kleinen Gemeinwesen war das Stimmrecht auf 14, in Schwyz, Glarus und Appenzell auf das erfüllte 16. Altersjahr angesetzt“".

47 I. Müller, Ursern im frühen Spätmittelalter 1300-1433, in: Der Geschichtsfreund. Mitteilungen des Historischen Vereins der fünf Orte Luzern, Uri, Schwyz, Unterwalden ob und nid dem Wald 135 (1982), S. 171 (226). 
Linders Hinweis auf die Subsistenzwirtschaft ${ }^{48}$ gibt auch ein Erklärungsmodell, welches das lange Ausbleiben des Frauenstimmrechts in einer Gesellschaft der Ehr- und Wehrhaften unter damaligen Zeitumständen plausibel erscheinen lässt: Tagelange Abwesenheit der ganzen Familienleitung war in einer Subsistenzwirtschaft kaum denkbar, und die Waffe als Stimmausweis prädestinierte einzig die Männer zur Teilnahme an der Landsgemeinde.

Die Erkenntnisse der Geschichtsforschung über eine starke Rechtsstellung gewisser Frauen in bestimmten zivilrechtlichen und gesellschaftlichen Vorgängen passen gut zum Befund, dass die Stellung der Frau erst in der frühen Neuzeit deutlich abgewertet wurde, nachdem die Renaissance auch in städtischen Strukturen den Männern ein Bildungsmonopol verschafft und Frauen aus ihren vormaligen Tätigkeiten in Medizin und Fürsorge verdrängt hatte ${ }^{49}$. Reformation und Gegenreformation wiesen dann Mann und Frau im Haushalt ihre neuzeitlichen Rollen zu, „worin die Frau für die Erziehung des Nachwuchses im Geiste des staatlich-konfessionellen Programms verantwortlich“" wurde ${ }^{50}$. Die großen

Linder, Universalität (Fn. 38), S. 213 f. nach einem Hinweis auf die Gültigkeit etwa der goldenen Regel oder des Prinzips nemini nocere kritisch zum uneingeschränkten Postulat der Menschenrechte im westlich-marktwirtschaftlichen Verständnis: „Solche Begründungen sind freilich blind für zwei wesentliche Punkte: erstens übersehen sie regelmässig die Frage gesellschaftlicher Ressourcen, deren Vorhandensein oder Fehlen andere Überlebensstrategien und damit auch andere Antworten der Moral erfordern, und zweitens beschäftigen sie sich kaum mit der Frage, wie sich gesellschaftliche Systeme von Moral überhaupt sinnhaft konstituieren und wie sie wirken können. - Beide Punkte seien zunächst erläutert am Beispiel von Gesellschaften, deren prekäre Ressourcenlage keine ausreichenden Lebenschancen für alle ihrer Mitglieder gewährt. [...] Nun sind freilich viele Gesellschaften weit davon entfernt, mit einer produktiven Erwerbswirtschaft und über eine ausreichende Zahl an Erwerbsarbeitenden jene Mittel bereitstellen zu können, die eine sozialstaatliche Versorgung der Alten und Kranken garantieren und so die Familie entlasten könnten. In vielen Entwicklungsgesellschaften lebt ein erheblicher Teil der Bevölkerung nach wie vor entweder von der Subsistenzwirtschaft oder aber stranden in den städtischen Slums. Grundfunktionen wie Produktion, Verteilung und Solidarität, teilweise Schutz und Sicherheit, sind nach wie vor durch familiale Strukturen geprägt.“

49 M. Senn, Rechtsgeschichte - ein kulturhistorischer Grundriss, 3. Aufl. 2003, S. 118 („Die Stellung der Frau verschlechtert sich erst in der frühen Neuzeit. Diese Verschlechterung ist die Folge von Renaissance, Rezeption und Reformation") mit Fn. 46. Die römischrechtliche Rechtsfigur des pater familias vermochte nämlich in der ziemlich wissenschaftsresistenten, hauptsächlich am germanischen und mündlich tradierten Recht orientierten Eidgenossenschaft nur langsam $\mathrm{Fuß} \mathrm{zu}$ fassen. Immerhin höhlten römischrechtliche Kategorien von Eigentum und Verfügungsmacht auch in der Schweiz nach und nach, wenn auch langsamer, die genossenschaftlichen Leihestrukturen des Mittelalters auf, an denen die Frauen teilgehabt hatten.

50 Senn, Rechtsgeschichte (Fn. 49), S. 118 sowie 139: „Die normative und soziale Schlechterstellung der Frau gegenüber dem Mann, die in den spätmittelalterlichen Gesellschaftsstrukturen trotz zunehmender Individualisierung gegeben ist, verschärft sich mit der Konfessionalisierung der Rechts- und Gesellschaftsordnungen der frühen Neuzeit. Die Frau wird zunehmend in die Rolle der Verantwortlichen für die Durchsetzung der staatlichen 
Zwangsumsiedlungen konfessioneller Minderheiten nach der Glaubensspaltung erschwerten auch die soziale Kontrolle der Stimmberechtigung an der Landsgemeinde; in einer nicht alphabetisierten Gesellschaft war das Seitengewehr ein praktisches Mittel zur Verhinderung der Teilnahme Nicht-Stimmberechtigter. Es stimmt übrigens keineswegs, dass erst Mary Wollstonecraft (1759-1797) und Olympe de Gouges (1748-1793) für die Frauen Mitbestimmungsrechte reklamiert hätten; zu dieser Erkenntnis war 1622 bereits die Autodidaktin und Montaignes „Wahltochter“ Marie le Jars de Gournay (1565-1645) in ihrem Traktat über die Gleichheit von Frauen und Männern gelangt $t^{51}$.

Die Schweiz wurde erst im 19. Jahrhundert durch die Volksschulbewegung alphabetisiert. Die Demokratie in der Schweiz ist also weit älter als die breite Verankerung von Lesen und Schreiben in der Bevölkerung. Hinter dem langen Ausschluss der Frauen vom Stimm- und Wahlrecht verbirgt sich weit weniger ideologische denn eine an pragmatisch-praktischen Errungenschaften orientierte Gewohnheit: Als es darum ging, stimmberechtigte von nicht stimmberechtigten Einwohnern abzugrenzen - eine bezeichnenderweise nach der Glaubensspaltung akzentuiert auftretende Forderung - kannten die Landsgemeindeteilnehmer einander in einer schon allein durch die religionsbedingt auftretende Vertreibung der Minderheiten in andere Kantone mobileren Gesellschaft zunehmend weniger. Dieser Landsgemeinde mit der Verlesung von Anträgen, der direkten Diskussion und schließlich der offenen Abstimmung über sie genügten einige wenige des Lesens und Schreibens kundige Personen. Aber die Stimmrechtskontrolle bedurfte einer Regelung, die öffentliche Kontrolle durch die gesamte Bevölkerung direkt im Ring und so das Aussondern Nicht-Stimmberechtigter ermöglichte. Der Degen oder das Seitengewehr ermöglichte dies denkbar einfach und wirksam.

und konfessionellen Erziehungsprogramme innerhalb der eigenen Familie gedrängt", sowie ebd., Fn. 51: „Die Schlechterstellung hat daher nichts mit dem angeblich ,dunklen“ Mittelalter, sondern mit der Konfessionalisierung der familiären Lebensbedingungen und den staatlichen Erziehungsprogrammen der frühen Neuzeit zu tun. Erst die Aufklärung des 18. Jahrhunderts wird hier wieder etwas Licht hineinbringen. Doch contre coeur de la révolution mit ihrer Doktrin der égalité bietet das Eherecht des, Code Civil' von 1804 das Anschauungsbeispiel, wie sich der bürgerliche Militarismus auf das geschlechtsspezifische Rollenverständnis [...] negativ auswirkt. Auch der Sozialdarwinismus und die kirchlich-konservativen Anschauungen der Konfessionen tragen im 19. Jahrhundert hierzu bei." (Hervorhebung i.O.).

51 Vgl. das Zitat bei M. Senn/L. Gschwend, Rechtsgeschichte II - Juristische Zeitgeschichte, 2. Aufl. 2004, S. 120 f.: „Die Mehrzahl derer, die für die Sache der Frauen und gegen die anmassende Vorrangstellung eintreten, welche die Männer beanspruchen, drehen den Spiess einfach um und verleihen statt dessen den Frauen den höheren Rang. Da ich für meinen Teil alle Extreme vermeide, begnüge ich mich damit, sie den Männern gleichzustellen, denn die Überlegenheit ist in dieser Hinsicht ebenso wie die Unterlegenheit wider die Natur." 


\section{Moderne}

Wie stark diese rein praktische Seite des Männerstimmrechts in der Schweiz verankert war und nachwirkte, mag der nachfolgende Blick in die Gesetzgebung zweier Landsgemeindekantone aufzeigen:

Das Landsgemeinde-Reglement vom 4. Dezember 1908 für den Kanton Appenzell Ausserrhoden legte in $\S 3$ folgendes fest: „Acht Tage vor der Landsgemeinde ist eine Publikation im Amtsblatt zu veröffentlichen und in allen Gemeinden in Plakatform anzuschlagen. Dieselbe soll eine gedrängte Aufzählung der Verhandlungsgegenstände enthalten, nebst der Einladung an alle nach der Verfassung stimmberechtigten Kantonseinwohner, zur vorgeschriebenen Zeit, in anständiger Kleidung und mit einem Seitengewehr versehen, bei der in Art. 40 der Kantonsverfassung bestimmten Busse am Versammlungsorte zu erscheinen und den Verhandlungen von Anfang an bis zum Schlusse beizuwohnen.“

Nachdem die Ausserrhodener (Männer-)Landsgemeinde am 30. April 1989 den Frauen auf kantonaler Ebene das Stimmrecht zuerkannt hatte, wurde diese Bestimmung am 11. Dezember 1989 so abgeändert, dass die Teilnehmenden „,in anständiger Kleidung, Männer mit Seitengewehr" zur Landsgemeinde zu erscheinen hätten. Erst mit der Aufgabe der Landsgemeinde 1997 wurde die Verordnung samt dieser Bestimmung hinfällig.

Die Verordnung des Kantons Appenzell Innerrhoden vom 21. November 1924 betreffend die Landsgemeinde und die Gemeindeversammlungen schrieb in Art. 8 kurz und bündig vor: „Als einziger Stimmrechtsausweis gilt das Seitengewehr."

Als das Bundesgericht mit Urteil vom 29. November 1990 die Innerrhodener Männer schliesslich verpflichtete, den Frauen das Stimmrecht in kantonalen Angelegenheiten zuzuerkennen, wurde dieser Art. 8 am 11. März 1991 abgeändert; in dieser Fassung gilt die Bestimmung bis heute ${ }^{52}$ : „Als Stimmrechtsausweis gilt die Stimmkarte, für Männer auch das Seitengewehr. ${ }^{\text {"53 }}$ 313 (NW) und 323 (OW). Innerrhodens 160.410). Vgl. auch unter http://www.ai.ch/de/politik/sitzung/ (zuletzt besucht am 17.6.2012; Hervorhebungen nicht i.O.). 


\begin{tabular}{|c|c|c|c|c|c|c|c|c|c|}
\hline \multirow[t]{2}{*}{ Kanton } & \multirow{2}{*}{$\begin{array}{l}\text { Einführung } \\
\text { in der } \\
\text { Volksab- } \\
\text { stimmung }\end{array}$} & \multicolumn{2}{|c|}{$\begin{array}{l}\text { Stimm- und } \\
\text { Wahlrecht }\end{array}$} & \multicolumn{6}{|c|}{$\begin{array}{l}\text { Vorangegangene kantonale Volksabstimmungen }{ }^{54} \\
\mathrm{LG}=\text { Landsgemeinde }\end{array}$} \\
\hline & & $\begin{array}{l}\text { kanto- } \\
\text { nal }\end{array}$ & $\begin{array}{l}\text { kom- } \\
\text { munal }\end{array}$ & 1. & 2 & 3. & 4. & 5. & 6. \\
\hline Zürich & 15.11 .1970 & $\mathrm{X}$ & $\mathrm{X}$ & 8.2 .1920 & $\begin{array}{c}18.2 .1923 \\
\text { kommunal }\end{array}$ & 30.11 .1947 & 5.12 .1954 & 20.11 .1966 & $\begin{array}{l}14.9 .1969 \\
\text { kommunal }\end{array}$ \\
\hline Bern & \begin{tabular}{|l|}
12.12 .1971 \\
\end{tabular} & $\mathrm{X}$ & $\mathrm{X}$ & $\begin{array}{c}4.3 .1956 \\
\text { kommunal }\end{array}$ & $\begin{array}{l}18.2 .1968 \\
\text { kommunal }\end{array}$ & & & & \\
\hline Luzern & 25.10 .1970 & $\mathrm{X}$ & $\mathrm{X}$ & $\begin{array}{l}4.12 .1960 \\
\text { kommunal }\end{array}$ & & & & & \\
\hline Uri & 5.3 .1972 & $\mathrm{X}$ & $\mathrm{X}$ & 30.1 .1972 & & & & & \\
\hline Schwyz & 5.3 .1972 & $\mathrm{X}$ & $\mathrm{X}$ & & & & & & \\
\hline Obwalden & 30.4 .1972 & $\mathrm{X}$ & $\mathrm{X}$ & 19.5 .1968 & & & & & \\
\hline Nidwalden & 30.4 .1972 & $\mathrm{X}$ & $\mathrm{X}$ & 10.10 .1956 & & & & & \\
\hline Glarus & 2.5 .1971 & $\mathrm{X}$ & $\mathrm{X}$ & $\begin{array}{l}1.5 .1921 \\
\text { LG }\end{array}$ & $\begin{array}{c}7.5 .1961 \\
\text { kommunal } \\
\text { LG }\end{array}$ & $\begin{array}{c}7.5 .1967 \\
\text { kommunal } \\
\text { LG }\end{array}$ & & & \\
\hline Zug & 7.2 .1971 & $\mathrm{X}$ & $\mathrm{X}$ & & & & & & \\
\hline Freiburg & 7.2 .1971 & $\mathrm{X}$ & $\mathrm{X}$ & \begin{tabular}{|l|}
4.11 .1948 \\
\end{tabular} & & & & & \\
\hline Solothurn & 6.6 .1971 & $\mathrm{X}$ & $\mathrm{X}$ & 26.6 .1966 & 18.2 .1968 & \begin{tabular}{|l|}
15.11 .1970 \\
\end{tabular} & & & \\
\hline $\begin{array}{l}\text { Basel- } \\
\text { Stadt }\end{array}$ & 26.6 .1966 & $\mathrm{X}$ & $\mathrm{X}$ & 8.2 .1920 & 15.5 .1927 & 16.6 .1946 & 5.12 .1954 & 3.11 .1957 & 26.6 .1966 \\
\hline $\begin{array}{l}\text { Basel- } \\
\text { Landschaft }\end{array}$ & 23.6 .1968 & $\mathrm{X}$ & $\mathrm{X}$ & 8.7 .1946 & 15.5 .1955 & 13.3 .1966 & 4.6 .1967 & 26.6 .1968 & $\begin{array}{c}27.9 .1970 \\
\text { kommunal }\end{array}$ \\
\hline $\begin{array}{l}\text { Schaff- } \\
\text { hausen }\end{array}$ & 7.2 .1971 & $\mathrm{X}$ & $\mathrm{X}$ & 28.5 .1967 & 14.9 .1969 & & & & \\
\hline \multirow{2}{*}{$\begin{array}{l}\text { Appenzell } \\
\text { A.Rh. }\end{array}$} & 30.4 .1972 & - & $\mathrm{X}$ & & & & & & \\
\hline & $\begin{array}{c}30.4 .1989 \\
\text { LG }\end{array}$ & $\mathrm{X}$ & & 25.4 .1976 & 29.4 .1979 & $29.4 .1984^{55}$ & & & \\
\hline $\begin{array}{l}\text { Appenzell } \\
\text { I.Rh. }\end{array}$ & $\underset{56}{26.4 .1992}$ & $\mathrm{X}$ & $\mathrm{X}$ & 25.4 .1976 & 29.4 .1990 & & & & \\
\hline St. Gallen & 23.1 .1972 & $\mathrm{X}$ & $\mathrm{X}$ & 4.9 .1921 & & & & & \\
\hline
\end{tabular}

54 Dazu statt vieler vgl. W. Seitz, Dreissig Jahre Frauenstimmrecht in der Schweiz. Die Vertretung der Frauen in den politischen Institutionen: Entwicklung seit 1971 und aktueller Stand. Referat vorgetragen an der Veranstaltung des Verbandes für Frauenrechte in Neuchâtel, 10.2.2001 = http://www.werner-seitz.ch/?a=311\&o=R_2001_DreissigJahre.htm\%2330JahreFrauenstimmrecht (zuletzt besucht am 17.6.2012); B. Mesmer, Staatsbürgerinnen ohne Stimmrecht. Die Politik der schweizerischen Frauenverbände 19141971, 2007; Botschaft des Bundesrates vom 22.2.1957 über die Einführung des Frauenstimm- und -wahlrechts in eidgenössischen Angelegenheiten, in: Bundesblatt (BB1.) 1957 I S. 665, sowie Botschaft des Bundesrates vom 23.12.1969 über die Einführung des Frauenstimm- und -wahlrechts in eidgenössischen Angelegenheiten, in: BB1. 1970 I S. 61 (insb. $70 \mathrm{ff}$.).

55 Kantonale Volksinitiative für eine Konsultativabstimmung über die Einführung des Frauenstimmrechts abgelehnt.

56 Der zitierte Entscheid des Bundesgerichts vom 27.11.1990 (BGE 116 Ia 359) hatte die Appenzeller Männer zur Gewährung des kantonalen Frauenstimmrechts gezwungen, vgl. BB1. 1993 II S. 196. 


\begin{tabular}{|l|c|c|c|c|c|c|c|l|l|}
\hline $\begin{array}{l}\text { Graubün- } \\
\text { den }\end{array}$ & 5.3 .1972 & $\mathrm{X}$ & $\mathrm{X}$ & 7.10 .1962 & 20.10 .1968 & $27.2 .1983^{57}$ & & & \\
\hline Aargau & 7.2 .1971 & $\mathrm{X}$ & $\mathrm{X}$ & & & & & & \\
\hline Thurgau & 12.12 .1971 & $\mathrm{X}$ & $\mathrm{X}$ & 26.1 .1969 & & & & & \\
\hline Tessin & 10.10 .1969 & $\mathrm{X}$ & $\mathrm{X}$ & 8.11 .1946 & $\begin{array}{c}29.1 .1962 \\
\text { kommunal }\end{array}$ & 24.4 .1966 & 10.10 .1969 & & \\
\hline Waadt & 1.2 .1959 & $\mathrm{X}$ & $\mathrm{X}$ & $\begin{array}{l}25.2 .1951 \\
\text { kommual }\end{array}$ & & & & & \\
\hline Wallis & 12.4 .1970 & $\mathrm{X}$ & $\mathrm{X}$ & & & & & & \\
\hline Neuenburg & 27.9 .1959 & $\mathrm{X}$ & $\mathrm{X}$ & 29.6 .1919 & $\begin{array}{c}9.11 .1941 \\
\text { kommunal }\end{array}$ & $\begin{array}{l}14.3 .1948 \\
\text { kommunal }\end{array}$ & & & \\
\hline Genf & 6.3 .1960 & $\mathrm{X}$ & $\mathrm{X}$ & 16.10 .1921 & 1.12 .1940 & 29.9 .1946 & 30.11 .1953 & & \\
\hline Jura & $20.3 .1977^{58}$ & $\mathrm{X}$ & $\mathrm{X}$ & & & & & & \\
\hline Schweiz & 7.2 .1971 & & & 1.2 .1959 & & & & & \\
\hline
\end{tabular}

Interessanterweise offenbart ein Blick in die Geschichte - die beiden bedeutendsten Schübe erlebte das Frauenwahlrecht im Anschluss an die beiden Weltkriege (vgl. Tabelle 1) - weltweit starke indirekte Zusammenhänge zwischen Kriegsdienst und Frauenstimmrecht: „Die prominente (auch propagandistische) Symbolfunktion der Frauen an der ,Heimatfront' stellte für die Zeitgenossen offenbar einen bemerkenswerten Kontrast zum Scheitern romantisch-heroischer Männlichkeitsideale in den Schützengräben dar. [...] Im Bereich der Geschlechterwahrnehmungen ist daher an die Stelle des Emanzipationsmodells zunehmend die Vorstellung einer Krise der Männlichkeit getreten, die sich für die Zeitgenossen als spektakuläre ,Verweiblichung' der Männer oder auch des gesamten Zeitalters darstellte. [...] Die Übertragung des weiblich codierten psychiatrischen Vorkriegsdiskurses der ,Hysterie“ und des Krankheitsbildes der ,Neurasthenie“ auf die traumatisierten ,Kriegszitterer' hat ein Übriges zur Verunsicherung der männlichen Geschlechteridentität beigetragen. “59

57 Verpflichtung der Gemeinden zur Einführung des Frauenstimmrechts auf Gemeindeebene abgelehnt.

58 Volksabstimmung über die Verfassung des 1978 neu gegründeten Kantons Jura.

59 A. Reimann, Der Erste Weltkrieg - Urkatastrophe oder Katalysator?, in: APuZ 2004 Nr. 29/30 S. 30 (34 f. Fn. 26) unter Hinweis auf J. Radkau, Das Zeitalter der Nervosität. Deutschland zwischen Bismarck und Hitler, 1998. Zu diesen Zusammenhängen vgl. auch J.L. Herman, Die Narben der Gewalt. Traumatische Erfahrungen verstehen und überwinden, 2003, bes. S. $21 \mathrm{ff}$. 
Tabelle 3: Rechtsgrundlagen gesamtstaatlicher Einführung des Frauenstimmrechts

\begin{tabular}{|c|c|c|}
\hline Staat & 莺 & Bemerkungen und Quellen $^{60}$ \\
\hline Spanien & $\begin{array}{l}1867 \\
1931 \\
1945 \\
\end{array}$ & $\begin{array}{l}\text { Constitución v. } 1.6 .1869 \text { Art. } 1 \text { Ziff. } 1 \text { in Verbindung mit Art. 16, } 62 \text { und } 66 \\
\text { (GM 573, 575, } 580 \text { f.); Constitución v. 9.12.1931 Art. } 36 \text { (GM 605); Gesetz } \\
\text { über den Volksentscheid v. 22.10.1945 Art. } 2 \text { (GM 635; MT 551) }\end{array}$ \\
\hline Neuseeland & 1893 & Electoral Act 1893 \\
\hline Australien & 1902 & Commonwealth of Australia Constitution Act 1900, Sect. 8 und 30 \\
\hline Norwegen & 1913 & $\begin{array}{l}\text { Grundgesetz v. 4.11.1814, Änderung v. 11.6./7.7.1913 von } \S 50 \text { Ziff. } 1 \text { und } 2 \\
\text { (GM 724; MT 341) }\end{array}$ \\
\hline Island & 1915 & Grundgesetz Dänemarks v. 5.6.1915 $\S \S 30,34$ und 35 (GM 1702 f.) \\
\hline Dänemark & 1915 & Grundgesetz v. 5.6.1915 $\S \S 30,34$ und 35 (GM 1702 f.) \\
\hline Kanada & 1917 & $\begin{array}{l}\text { The British North America Act v. 29.3.1867, Änderung } 1917 \text { von Sect. } 41 \\
\text { Subsect. } 2\end{array}$ \\
\hline Niederlande & 1917 & $\begin{array}{l}\text { Grundgesetz v. 24.8.1815/15.11.1887, Änderung } 1917 \text { von Art. } 80 \text { Abs. } 1 \text { und } \\
84 \text { (GM 932; MT } 311 \text { f.) }\end{array}$ \\
\hline Deutschland & 1918 & $\begin{array}{l}\text { Aufruf des Rats der Volksbeauftragten vom 12.11.1918, Verordnung über die } \\
\text { Wahlen zur verfassunggebenden deutschen Nationalversammlung (Reichs- } \\
\text { wahlgesetz) vom 30.11.1918 } \S 2^{61} \\
\text { Weimarer Reichsverfassung v. } 11.8 .1919 \text { Art. } 22 \text { (GM 809; GF 196) }\end{array}$ \\
\hline Irland & 1918 & Constitution Act v. 25.10 .1922 Art. 14 (GM 2010 f.) \\
\hline Luxemburg & 1918 & $\begin{array}{l}\text { Verfassung v. 17.10.1868, Änderung v. 15.5.1918 von Art. } 52 \text { (GM 1336, MT } \\
286 \text { f.) }\end{array}$ \\
\hline Österreich & 1919 & $\begin{array}{l}\text { Gesetz v. } 12.11 .1918 \text { Art. } 9 \text { (GM 1535); Bundes-Verfassungsgesetz v. } \\
\text { 1.10.1920 Art. } 26 \text { Abs. } 1 \text { (GM 1559) }\end{array}$ \\
\hline $\begin{array}{l}\text { Tschecho- } \\
\text { slowakei }\end{array}$ & 1919 & Verfassung v. 29.2.1920 $99(\mathrm{GM} 1831)$ \\
\hline Polen & 1919 & Verfassung v. 17.3.1921 Art. 12 und 13 (GM 386) \\
\hline USA & 1919 & Constitution Amendment XIX, in Kraft getreten 1920 (GM 159) \\
\hline Estland & 1920 & Grundgesetz v. $15.6 .1920 \S \S 27-29$ und 37 (GM 1860 f.) \\
\hline
\end{tabular}

60 Literatur: P.C. Mayer-Tasch (Hrsg.), Die Verfassungen Europas, 1966 (MT); ders./ I. Contiades (Hrsg.), Die Verfassungen der nicht-kommunistischen Staaten Europas, 2. Aufl. 1975 (MT/C); D. Gosewinkel/J. Masing (Hrsg.), Die Verfassungen in Europa 17891949. Wissenschaftliche Textedition unter Einschluss sämtlicher Änderungen und Ergänzungen sowie mit Dokumenten aus der englischen und amerikanischen Verfassungsgeschichte, 2006 (GM); H. Baumann/G. Brehme/M. Ebert (Hrsg.), Die Verfassungen der anglophonen Staaten des subsaharischen Afrikas (Verfassungen der Länder Afrikas sowie des Nahen und Mittleren Ostens 3), 2002 (BBE); G. Franz (Hrsg.), Staatsverfassungen. Eine Sammlung wichtiger Verfassungen der Vergangenheit und Gegenwart in Urtext und Übersetzung, 3. Aufl. 1975 (GF); Revue de droit hongrois 1984, S. 23 ff. (RDH); H. Roggemann, Die Verfassungen der sozialistischen Staaten, 1980 (R).

61 Für die Hintergründe vgl. K. Canning, Das Geschlecht der Revolution - Stimmrecht und Staatsbürgertum 1918/19, in: A. Gallus (Hrsg.), Die vergessene Revolution von 1918/19, 2010, S. 84-116. 


\begin{tabular}{|l|l|l|}
\hline Lettland & 1922 & Verfassung v. 15.2.1922 Art. 8 (GM 1946) \\
\hline Litauen & 1922 & Verfassung v. 1.8.1922 § 24 (GM 1959) \\
\hline Ungarn & 1949 & Verfassung v. 18.8.1949 §§ 62, 71 ff. (RDH 1984 34-36; R 563-565) \\
\hline Schweden & 1921 & Regierungsform v. 6.6.1809, Änderung von § 4 (GM 643) \\
\hline Portugal & 1933 & $\begin{array}{l}\text { Politische Verfassung v. 11.4.1933 Art. 8 und 85 (GM 1264 und 1279; MT } \\
426 \text { und 441) }\end{array}$ \\
\hline Frankreich & 1944 & Constitution v. 27.10.1946 Art. 4 (GM 361) \\
\hline Italien & 1945 & Costituzione v. 27.12.1947 Art. 48 (GM 1389; MT 256) \\
\hline Japan & 1946 & Verfassung v. 3.5.1947 Art. 15 Abs. 3 und Art. 44 (GF 545 und 549) \\
\hline Belgien & 1948 & $\begin{array}{l}\text { Verfassung v. 7.2.1831, Änderung v. 7.2.1921 Art. 47 Übergangsbe- } \\
\text { stimmung, Art. 50 Abs. 2; Änderung v. 15.10.1921 Art. 53 Übergangsb- } \\
\text { stimmung: Ausführungsgesetz (MT/C 46; GF 66-70) }\end{array}$ \\
\hline $\begin{array}{l}\text { Griechen- } \\
\text { land }\end{array}$ & 1952 & Verfassung v. 1.1.1952 authentische Interpretation zu Art. 70 und 66 \\
\hline Schweiz & 1971 & Änderung v. 7.2.1971 der Bundesverfassung v. 29.5.1874 Art. 72 \\
\hline $\begin{array}{l}\text { Liechten- } \\
\text { stein }\end{array}$ & 1984 & Änderung v. 1.7.1984 der Verfassung v. 5.10.1921 Art. 2962 \\
\hline
\end{tabular}

\section{Zeitlicher Abstand zwischen Unabhängigkeit bzw. Französischer Revolution und Judenemanzipation, Sklavereiverbot und Frauenstimmrecht nach Reli- gionen bzw. Konfessionen}

Zunächst erscheint es plausibel, einen Gradmesser für die Einräumung des Frauenstimmrechts und damit der politischen Gleichberechtigung im Vergleich mit anderen mittlerweile weltweit anerkannten Kriterien des Diskriminierungsverbots zu suchen. Dafür bieten sich Regeln zwingenden Völkerrechts wie das Verbot von Sklaverei und Rassismus umso stärker an, als die Analyse der Geschichte deutliche Parallelen zwischen Frauen und Sklaven im Stimmrechtsausschluss ergeben hat ${ }^{63}$. Vergleicht man demnach weltweit die Dauer zwischen staatlicher Unabhängigkeit oder - im Falle vorbestandener Unabhängigkeit - den Forderun-

62 Vorangegangene (Männer-)Urnengänge zur Einführung des Frauenstimmrechts im Fürstentum Liechtenstein erinnern an die Renitenz von Mehrheiten des ,starken“ Geschlechts in manchen Schweizer Kantonen (vgl. Tabelle 2 hiervor). In Liechtenstein lehnten die Männer landesweit das Frauenstimmrecht am 28.2.1971 und am 11.2.1973 ab und nahmen es am 1.7.1984 an; vgl. die Resultate zusammengestellt bei P. Vogt, 125 Jahre Landtag, 1987, S. 247, 248 und 251 sowie bei W. Marxer, 20 Jahre Frauenstimmrecht - Eine kritische Bilanz. Erweiterte Fassung eines Vortrages zur Jubiläumsveranstaltung ,20 Jahre Frauenstimmrecht' am 26.6.2004 in Vaduz (Beiträge Liechtenstein-Institut 19), 2004, S. 5 ff. Ziff. 4.3, unter http://www.liechtenstein-institut.li/Portals/0/contortionistUniverses/408/rsc/Publikation_downloadLink/LIB_19.pdf(zuletzt besucht am 17.6.2012).

63 Diese Relation wird auch auf einer persönlichen Ebene erkennbar, wie beispielsweise die Biographie der amerikanischen Bürgerrechtlerin, führenden Persönlichkeit der Frauenrechtsbewegung und Aktivistin der Abolitionismus-Bewegung Elizabeth Cady Stanton zeigt, vgl. S. Stanley Holton, From Anti-Slavery to Suffrage Militancy: The Bright Circle, Elizabeth Cady Stanton and the British Women's Movement, in: C. Daley/M. Nolan (Hrsg.), Suffrage \& Beyond, New York 1994, S. 213 ff. 
gen Mary Wollstonecrafts oder Olympe de Gouges ', d.h. den während der Französischen Revolution aufgebrochenen Ideen politischer Gleichstellung der Geschlechter und einerseits der Ächtung der Sklaverei ${ }^{64}$, anderseits der Einführung des Frauenstimmrechts und dritterseits - soweit überhaupt möglich ${ }^{65}$ - der Emanzipation der Juden, so zeigt sich freilich rasch, dass dadurch ein verzerrtes Bild entsteht: Gebiete Afrikas, welche primär Opfer der Sklaverei stellten, errangen ihre Eigenstaatlichkeit in aller Regel sehr spät und waren für die Verpönung der regelmäßig stark rassistisch unterfütterten Sklaverei ebenso wie für das Frauenstimmrecht bereits in ihrer Ursprungsverfassung sensibilisiert. Misst man diese Dauer nun an der heutigen religiösen Durchmischung der Staaten, so zeigen sich immerhin einige überraschende Zusammenhänge. Dieser Befund ist freilich mit der nötigen Vorsicht zu genießen, weil er auf die praktisch erst heute verfügbaren $^{66}$ und vergleichbaren Daten abstellt. Für schlüssigere Aussagen wäre freilich die historische Entwicklung der religiösen Zusammensetzung der Bevölkerung aller untersuchten Staaten insbesondere im Zeitpunkt der Einführung des Frauenstimmrechts vonnöten, und diese ist heute zumeist gar nicht greifbar, sei es, weil die meisten Staaten die Standards ihrer statistischen Erhebungen erst lange nach Einführung des Frauenstimmrechts angehoben haben, sei es, weil ganze Kontinente gebietsweise Eigenstaatlichkeit erst in der zweiten Hälfte des 20. Jahrhunderts (zurück) erlangt haben, sei es schließlich, weil sich kriegs- und/oder wirtschaftsbedingte, Kontinent- und damit religionsübergreifende Migrationsströme aufgrund neuer Transportmöglichkeiten gerade in den letzten beiden Jahrzehnten stark akzentuiert haben. Nachstehend sei der quantitative Anteil verschiedener Religionen und Konfessionen in den unter Tabelle 1 aufgeführten Staaten zusammengestellt:

64 Die Ratifikationsdaten der verschiedenen Staaten sind bei der UNO abrufbar unter http://treaties.un.org/Pages/ViewDetails.aspx?src=IND\&mtdsg_no=XVIII-3\&chapter= 18\&lang=fr (zuletzt besucht am 17.6.2012).

65 Nicht in allen heutigen Staaten der Erde gab es jüdische Minderheiten, die überhaupt um die Gewährung von Rechten ringen konnten; vgl. Tabelle 4 hiernach.

66 Die nachfolgenden Auswertungen stützen sich auf Central Intelligence Agency (CIA), The World Factbook, abrufbar unter: https:/www.cia.gov/library/publications/the-worldfactbook/index.html (zuletzt besucht am 17.6.2012; in Tabelle 4 zitiert als CIA 2012), sowie auf die Angaben in: Der neue Fischer Weltalmanach 2012. Zahlen, Daten, Fakten, 2011, passim (in Tabelle 4 zitiert als FA 2012 samt Seitenzahl). 


\begin{tabular}{|c|c|c|c|c|c|c|c|c|c|c|c|c|c|c|c|c|c|}
\hline \multirow{2}{*}{ Staat } & \multicolumn{8}{|c|}{ Religionen nach CIA 2012 (\%) } & \multicolumn{8}{|c|}{ Konfessionen CIA $2012(\%)$} & \multirow{2}{*}{ Bemerkungen } \\
\hline & $\mathrm{C}$ & $\mathrm{J}$ & M & $\mathrm{B}$ & $\mathrm{H}$ & $\mathrm{S}$ & $\mathrm{N}$ & - & $\mathrm{k}$ & $\mathrm{p}$ & o & su & $\mathrm{sc}$ & al & hi & $\mathrm{ma}$ & \\
\hline Neuseeland & 64 & & & 2 & 2 & & & 32 & 13 & 41 & & & & & & & \\
\hline Australien & 64 & & 2 & 2 & & & & 19 & 26 & 27 & 3 & & & & & & \\
\hline Finnland & 84 & & & & & & & 15 & & 83 & 1 & & & & & & \\
\hline Norwegen & 90 & & 2 & & & & & & 1 & 87 & & & & & & & \\
\hline Island & 88 & & & & & & & 3 & 3 & 85 & & & & & & & \\
\hline Dänemark & 97 & & 2 & & & & & & 2 & 95 & & & & & & & \\
\hline \begin{tabular}{|l|} 
Kanada \\
\end{tabular} & 70 & & 2 & & & & & 16 & 43 & 27 & & & & & & & \\
\hline Niederlande & 50 & & 6 & & & & & 42 & 30 & 20 & & & & & & & \\
\hline \begin{tabular}{|l|l} 
UdSSR \\
\end{tabular} & 22 & & 15 & & & & & & 1 & 1 & 20 & & & & & & \\
\hline Ukraine & 96 & 1 & & & & & & & 10 & 2 & 84 & & & & & & \\
\hline \begin{tabular}{|l|} 
Deutschland \\
\end{tabular} & 68 & & 4 & & & & & 28 & 34 & 34 & & & & & & & \\
\hline \begin{tabular}{|l|} 
Groß- \\
britannien
\end{tabular} & 72 & 1 & 3 & & 1 & & & 15 & & & & & & & & & $\begin{array}{l}\text { Konfessions- } \\
\text { angaben } 0\end{array}$ \\
\hline Irland & 92 & & & & & & & 4 & 87 & 5 & & & & & & & \\
\hline Luxemburg & 73 & 1 & 1 & & & & & 25 & 69 & 4 & & & & & & & $\begin{array}{l}\text { http://www. } \\
\text { religion.lu/ }\end{array}$ \\
\hline Österreich & 79 & & 4 & & & & & 12 & 74 & 5 & & & & & & & \\
\hline $\begin{array}{l}\text { Tschecho- } \\
\text { slowakei }\end{array}$ & 29 & & & & & & & 59 & 27 & 2 & & & & & & & \\
\hline \begin{tabular}{|l|} 
Polen \\
\end{tabular} & 91 & & & & & & & 8 & 90 & 1 & & & & & & & \\
\hline USA & 77 & 2 & 1 & & 1 & & & 4 & 26 & 51 & & & & & & & \\
\hline Ungarn & 75 & & & & & & & 15 & 55 & 20 & & & & & & & \\
\hline Schweden & 75 & & 4 & & & & & & 2 & 73 & & & & & & & $\begin{array}{l}\text { genauer FA } \\
2012418\end{array}$ \\
\hline Mongolei & & & 4 & 50 & & & 6 & 40 & & & & & & & 50 & & \\
\hline Ecuador & 95 & & & & & & & & 95 & & & & & & & & $\begin{array}{l}\text { FA } 2012 \text { 168: k } \\
85 \%\end{array}$ \\
\hline Sri Lanka & 6 & & 8 & 69 & 7 & & & & 6 & & & & & & & & \\
\hline Thailand & 1 & & 4 & 95 & & & & & & & & & & & & & \\
\hline Uruguay & 58 & & & & & & & 18 & 47 & 11 & & & & & & & \\
\hline Kuba & 65 & & & & & & & & 60 & 5 & & & & & & & \\
\hline Türkei & & & 99 & & & & & & & & & 70 & & 25 & & & FA 2012486 \\
\hline Indien & 2 & & 13 & & 81 & & & & & & & & & & & & \\
\hline Philippinen & 93 & & 5 & & & & & & 83 & 10 & & & & & & & \\
\hline $\begin{array}{l}\text { Dominika- } \\
\text { nische Re- } \\
\text { publik }\end{array}$ & 88 & & & & & & & 11 & 70 & 18 & & & & & & & $\begin{array}{l}\text { genauer FA } \\
2012166\end{array}$ \\
\hline Frankreich & 66 & & 4 & & & & & & 64 & 2 & & & & & & & $\begin{array}{l}\text { genauer FA } \\
2012179\end{array}$ \\
\hline Italien & 92 & & 2 & & & & & & 89 & 1 & 2 & & & & & & \begin{tabular}{|l|} 
genauer FA \\
2012254
\end{tabular} \\
\hline Liberia & 40 & & 10 & & & & 50 & & & & & & & & & & $\begin{array}{l}\text { genauer FA } \\
2012311\end{array}$ \\
\hline Albanien & 30 & & 70 & & & & & & 10 & & 20 & 70 & & & & & \\
\hline Japan & 2 & & & 71 & & 84 & & & & & & & & & & & $\begin{array}{l}\text { Viele Synkre- } \\
\text { tisten! }\end{array}$ \\
\hline Jugoslawien & & & & & & & & & & & & & & & & & \begin{tabular}{|l|} 
(In 6 Staaten \\
zerfallen)
\end{tabular} \\
\hline
\end{tabular}




\begin{tabular}{|l|l|l|l|l|l|l|l|l|l|l|l|l|l|l|l|l|l|}
\hline Rumänien & 99 & & 1 & & & & & & 5 & 8 & 86 & & & & & & \\
\hline El Salvador & 80 & & & & & & & 17 & 57 & 23 & & & & & & & \\
\hline Panama & 99 & & & & & & & & 85 & 14 & & & & & & & $\begin{array}{l}\text { FA } 2012 ~ 382: \\
\text { p } 10\end{array}$ \\
\hline Südafrika & 80 & & 2 & & & & & 15 & 7 & 73 & & & & & & & \\
\hline Argentinien & 92 & 2 & 2 & & & & & & 75 & 8 & & & & & & & $\begin{array}{l}\text { genauer FA } \\
2012\end{array}$ \\
\hline Bulgarien & 84 & 12 & & & & & & & & 83 & & & & & & \\
\hline China & 1 & & 1 & 7 & & & & 90 & & & & & & & & 7 & $\begin{array}{l}\text { genauer FA } \\
2012105\end{array}$ \\
\hline Myanmar & 4 & & 4 & 89 & & & & & 1 & 3 & & & & & & & \\
\hline Venezuela & 98 & & & & & & & & 90 & 8 & & & & & & & $\begin{array}{l}\text { genauer FA } \\
2012506\end{array}$ \\
\hline Belgien & 76 & 4 & & & & & 16 & 75 & 1 & & & & & & & $\begin{array}{l}\text { genauer FA } \\
2012 \text { 78 }\end{array}$ \\
\hline Israel & 2 & 76 & 19 & & & & & & & & & & & & & & \\
\hline Korea & 27 & & & 23 & & & & 49 & 7 & 20 & & & & & & & \\
\hline Chile & 87 & & & & & & & 8 & 70 & 17 & & & & & & & \\
\hline Costa Rica & 92 & & & & & & & 3 & 76 & 16 & & & & & & & \\
\hline $\begin{array}{l}\text { Griechen- } \\
\text { land }\end{array}$ & 98 & 1 & & & & & & & & 98 & & & & & & \\
\hline Schweiz & 75 & 4 & & & & & 20 & 39 & 31 & 2 & & & & & & $\begin{array}{l}\text { Strukturer- } \\
\text { hebung 2010 }\end{array}$ \\
\hline Spanien & 95 & & & & & & & & 94 & & & & & & & & \\
\hline
\end{tabular}

Legende zu Tabelle 4: Religionen sind VERSAL bezeichnet, Konfessionen in Kleinbuchstaben.

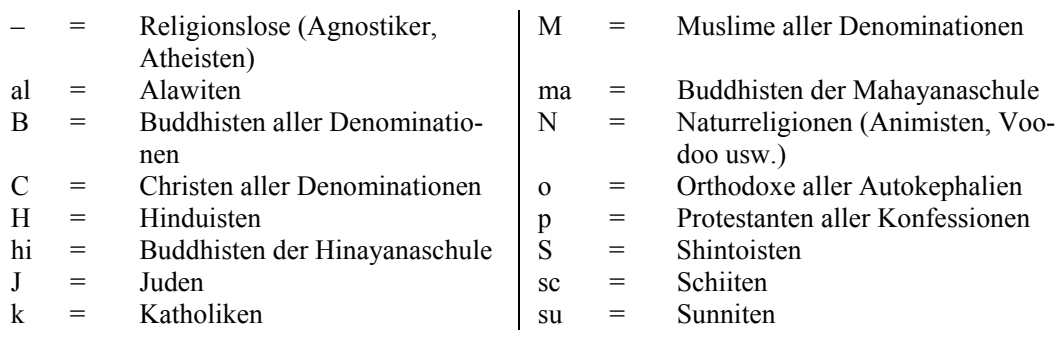

Dass interreligiös stark durchmischte Staaten ohne beherrschende Stellung einer Religion das Frauenstimmrecht besonders rasch eingeräumt haben, mag sich durch die schwache Stellung konservativ beharrender religiöser Kräfte erklären. Immerhin schneiden christlich konfessionsdurchmischte Staaten dabei im Unterschied zu muslimisch konfessionsdurchmischten Staaten ausgesprochen schlecht $\mathrm{ab}$, wofür angesichts der beidseits belasteten Vergangenheit in Sachen Versklavung anderer Völker vorderhand keine Erklärung plausibel erscheint. Gut schneiden in dieser Hinsicht die autokephalen orthodox-christlichen Staaten ab,

67 Abrufbar unter http://www.bfs.admin.ch/bfs/portal/de/index/news/04/01.html (zuletzt besucht am 23.6.2012). 
was vielleicht weniger mit der Religion an sich als mit dem fehlenden Zugang zu warmen Weltmeeren zu erklären sein könnte: Bis zur Ächtung der Sklaverei war der Wasserweg mit Abstand schnellster Transportweg (auch zur Entführung und Entwurzelung der versklavten Opfer) gewesen.

\section{Tabelle 5: Zusammenfassung Religionsübersicht und Rangfolge Ächtung der} Sklaverei

\begin{tabular}{|c|c|c|c|c|c|}
\hline Nr. & $\begin{array}{l}\text { Staaten mit überwiegender Konfession } \\
\text { (Lesebeispiel siehe nach Tabelle 5) }\end{array}$ & $\begin{array}{c}\text { + Jahre Skla- } \\
\text { vereiverbot } \\
\text { Ratifikation }\end{array}$ & $\begin{array}{c}\text { + Jahre Frau- } \\
\text { enwahlrecht } \\
\text { seit Unabhän- } \\
\text { gigkeit } \\
\text { (Bst. = Rang) }\end{array}$ & \begin{tabular}{|c} 
Jahre seit \\
Gouges $/$ Woll- \\
stonecraft \\
$1791 / 1792$ \\
(Bst. = Rang) \\
\end{tabular} & $\begin{array}{c}\text { Summe } \\
(\text { Kol. } d+e) \\
\text { (Bst. }= \\
\text { Rang) }\end{array}$ \\
\hline $\mathrm{a}$ & $\mathrm{b}$ & $\mathrm{c}$ & $\mathrm{d}$ & e & $\mathrm{f}$ \\
\hline 1 & Muslimisch konfessionell durchmischt & A 3 & B 0 & L 162 & D 162 \\
\hline 2 & Stark überwiegend jüdisch & B 7 & B 0 & H 156 & C 156 \\
\hline 3 & $\begin{array}{l}\text { Muslimisch stark überwiegend sunni- } \\
\text { tisch }\end{array}$ & C 10 & E 14 & M 170 & E 184 \\
\hline 4 & Interreligiös stark durchmischt & D 11.4 & A -4 & G 155 & B 151 \\
\hline 5 & $\begin{array}{l}\text { Christlich stark orthodox (unterschiedli- } \\
\text { cher Autokephalie) }\end{array}$ & E 23.3 & D 1.7 & C 148.5 & A 150.2 \\
\hline 6 & Überwiegend konfessionslos & F 97.8 & F 75 & A 136.5 & F 211.5 \\
\hline 7 & $\begin{array}{l}\text { Christlich stark protestantisch (unter- } \\
\text { schiedlicher Observanz) }\end{array}$ & G 153.4 & G 145 & D 149 & G 294 \\
\hline 8 & Christlich stark römisch-katholisch & H 162.6 & H 158 & F 153 & H 311 \\
\hline 9 & Stark überwiegend buddhistisch & I 245.5 & I 230 & B 142 & I 372 \\
\hline 10 & Stark überwiegend hinduistisch & K 314 & K 314 & K 160 & K 474 \\
\hline 11 & Christlich konfessionsdurchmischt & L 352.1 & L 356 & I 157 & L 513 \\
\hline \multirow[t]{2}{*}{12} & Muslimisch stark überwiegend schiitisch & M 502 & M 483 & E 150 & M 633 \\
\hline & Durchschnitt aller Staaten & 109.83 & 103.16 & 141.27 & \\
\hline
\end{tabular}

Lesebeispiele zu Tabellen 5 und 6: Israel als einziger mehrheitlich jüdischer Staat (Tabellen 5 und 6 je Zeile 2) führte das Frauenwahlrecht (Tabelle 5 Kolonne d = Tabelle 6 Kolonne c) direkt bei der Staatsgründung (1948) 156 Jahre nach den Publikationen Olympe de Gouges ' und Mary Wollstonecrafts ein, derweil es das Sklavereiverbot sieben Jahre später ratifizierte. Interreligiös stark dominierte Staaten erteilten ihren Frauen das Wahlrecht durchschnittlich vier Jahre vor der Unabhängigkeit, also noch zu Kolonialzeiten (Tabelle 5 Kolonne d Zeile 4).

Hinsichtlich des Frauenstimmrechts tauschen muslimisch-konfessionell durchmischte und interreligiös stark durchmischte Staaten in etwa ihre Plätze, derweil die übrigen relativen Rangierungen weitestgehend konstant bleiben. 


\begin{tabular}{|l|l|c|c|c|}
\hline Nr. & $\begin{array}{l}\text { Staaten mit überwiegender Konfession } \\
\text { (Lesebeispiel siehe nach Tabelle 5) }\end{array}$ & $\begin{array}{c}\text { + Jahre Frauen- } \\
\text { wahlrecht seit } \\
\text { Unabhängigkeit } \\
\text { (Bst. = Rang) }\end{array}$ & $\begin{array}{c}\text { Jahre seit Gouges/ } \\
\text { Wollstonecraft } \\
1791 / 1792 \\
\text { (Bst. = Rang) }\end{array}$ & $\begin{array}{l}\text { + Jahre Sklaverei- } \\
\text { verbot Ratifikation } \\
\text { Summe }\end{array}$ \\
\hline $\mathrm{a}$ & $\mathrm{b}$ & $\mathrm{c}$ & $\mathrm{d}$ & $\mathrm{e}$ \\
\hline 1 & Interreligiös stark durchmischt & A -4 & G 155 & 151 \\
\hline 2 & Stark überwiegend jüdisch & B 0 & H 156 & 156 \\
\hline 3 & Muslimisch konfessionell durchmischt & B 0 & L 162 & 162 \\
\hline 4 & $\begin{array}{l}\text { Christlich stark orthodox (unterschiedli- } \\
\text { cher Autokephalie) }\end{array}$ & D 1.7 & C 148.5 & 150.2 \\
\hline 5 & $\begin{array}{l}\text { Muslimisch stark überwiegend sunni- } \\
\text { tisch }\end{array}$ & E 14 & M 170 & 184 \\
\hline 6 & Überwiegend konfessionslos & F 75 & A 136.5 & 211.5 \\
\hline 7 & $\begin{array}{l}\text { Christlich stark protestantisch (unter- } \\
\text { schiedlicher Observanz) }\end{array}$ & G 145 & D 149 & 294 \\
\hline 8 & Christlich stark römisch-katholisch & H 158 & F 153 & 311 \\
\hline 9 & Stark überwiegend buddhistisch & I 230 & B 142 & 372 \\
\hline 10 & Stark überwiegend hinduistisch & K 314 & K 160 & 474 \\
\hline 11 & Christlich konfessionsdurchmischt & L 356 & I 157 & 513 \\
\hline 12 & Muslimisch stark überwiegend schiitisch & M 483 & E 150 & 633 \\
\hline
\end{tabular}

Insgesamt lässt sich also sagen, dass - an der religiösen Orientierung gemessen stark ,monokolore“ und religiös ausgerichtete Staaten sowohl bei der Ächtung der Sklaverei als auch bei der Einführung des Frauenwahlrechts tendenziell besonders zögerlich agierten. Spannend ist dabei nun aber, dass die Schweiz als christlich-konfessionell stark durchmischter Staat und mit relativ geringer direkter Berührung zur Sklaverei ${ }^{68}$ zur Einführung des Frauenstimmrechts besonders lange benötigte; bis zur flächendeckenden Einräumung des Frauenstimmrechts auf allen drei Staatsebenen der Eidgenossenschaft waren allein auf Bundes- und Kantonsebene weit über 100 Volksabstimmungen vonnöten. Nicht nur der deutsche Dichterfürst Johann Wolfgang Goethe, sondern auch der begeisterte und aufstrebende junge radikale Kämpfer für die Demokratie in der Schweiz Gott-

68 Immerhin waren verschiedene Schweizer Unternehmen am Dreieckshandel beteiligt. Vgl. dazu Bericht des Bundesrathes vom 2. Dezember 1864 an den h. Nationalrath, betreffend Strafbestimmungen gegen Schweizer in Brasilien, welche Sklaven halten, in: BB1. 1864 III S. 230 u. 373; H. Fässler, Reise in Schwarz-Weiss. Schweizer Ortstermine in Sachen Sklaverei, 2005; T. David/B. Etemad/J.M. Schaufelbuehl, Schwarze Geschäfte. Die Beteiligung von Schweizern an Sklaverei und Sklavenhandel im 18. und 19. Jahrhundert. Aus dem Französischen von B. Althaler, 2005; P. Purtschert/B. Lüthi/F. Falk (Hrsg.), Postkoloniale Schweiz. Formen und Folgen eines Kolonialismus ohne Kolonien, 2012. 
fried Keller vermochten für Mitsprache und Mitbestimmung der Frau im Staat kein Verständnis aufzubringen, wie die eingangs zitierten Verse zeigen. Am nächsten für die lange demokratische „Inkubationszeit“ in der Schweiz liegt die Erklärung, dass gerade die ausgeprägte Glaubensspaltung in der Eidgenossenschaft zur Zurückdrängung der Frau in die Rolle der Erziehenden am häuslichen Herd beigetragen hatte und dass die Reisläuferei (Söldnerwesen) in einer nicht alphabetisierten Gesellschaft die Kontrolle der Stimmberechtigung an der Landsgemeinde für jedermann am einfachsten anhand der Waffe feststellen ließ. Es ist kaum Zufall, dass das Frauenstimmrecht im Anschluss an die beiden Weltkriege jeweils primär in Nationen auf der (zumindest vorübergehenden) Verliererseite eingeführt wurde. Merkwürdig: Derweil im Ausland Dezimierung kombattanter Männer und die Zerstörung von Heldenmythen (Kriegszitterer, yperitgeschädigte Erblindete) auf breiter Front die Rolle der Frau in nationalen Notstandssituationen ins Licht rückte, blieb diese Rolle in der von beiden Weltkriegen verschonten Schweiz im Dunkeln: In der Schweiz hatten die Frauen doch in beiden Weltkriegen nicht weniger als im Ausland die einheimische Wirtschaft vor allem des Primärsektors praktisch alleine zu tragen, derweil ihre Männer ab der Mobilmachung unter den Waffen standen. Die glücklicherweise nicht benötigte Waffe konnte als Stimmrechtsausweis den Mythos nochmals um einige weitere Jahrzehnte aufrechterhalten.

\section{Vergleich der gewonnenen Erkenntnisse mit gängigen Erklärungsansätzen}

Der Ruf nach dem Frauenwahlrecht ertönte weltweit zu unterschiedlichen Zeitpunkten und in unterschiedlicher Lautstärke ${ }^{69}$. Weltweit wiederkehrend ist allerdings die Tatsache, dass die Frauen sich in Verbänden und Vereinen organisierten. In den meisten Ländern wurden gleich mehrere Frauen-Organisationen ins Leben gerufen, die sich ausschließlich oder unter anderem mit der Einführung des Frauenwahlrechts befassten ${ }^{70}$. Auch die starke internationale Vernetzung und

69 Eine Relation zwischen der ,Lautstärke‘ respektive der Heftigkeit und Militanz der Forderungen nach dem Frauenstimmrecht und dem Einführungszeitpunkt ist allerdings nicht erkennbar - (mit) ausschlaggebend waren jeweils weitere, von den Frauenbewegungen selbst nicht beeinflussbare Faktoren. Vgl. dazu N. Braun Binder, Gegen die Diskriminierung der Frau. Der Kampf für die Emanzipation. Widerstand im Kontext des Kampfs um das Frauenstimmrecht, in: H.H. v. Arnim (Hrsg.), Widerstand. Beiträge auf der 13. Speyerer Demokratietagung, 2012, S. 149 ff.

70 Vgl. nur etwa die Liste der Frauenverbände in: H. Rappaport, Encyclopedia of Women Social Reformers, Vol. II, Santa Barbara 2001, S. 775 ff. (Appendix: Organizations by English and Original Names), sowie einzelne Organisationen in: J. Hannam/M. Auchterlonie/K. Holden (Hrsg.), International Encyclopedia of Women's Suffrage, Santa Barbara 2000 . 
Zusammenarbeit der einzelnen Organisationen ist ein Merkmal des Kampfs um die Einführung des Frauenwahlrechts. Die Schweizer Frauen standen dem in nichts nach. Wie Beatrix Mesmer in ihren Untersuchungen aufzeigt, gehörten die Schweizerinnen bereits zu Beginn des 20. Jahrhunderts zu den am besten organisierten Frauen Europas ${ }^{71}$.

In der Regel wird die späte Einführung des Frauenstimmrechts in der Schweiz denn auch hauptsächlich mit dem Verweis auf die direkte Demokratie erklärt: die Einführung des Frauenstimmrechts war von der Zustimmung der Mehrheit der Männer abhängig, und diese war nicht einfach zu erlangen. Nationalrat Peter von Roten beschrieb die Situation pointiert: „Glauben Sie, in irgendeiner Staatsverfassung sei vorgesehen, dass die Entthronung eines Königs nur mit dessen $\mathrm{Zu}$ stimmung gemacht werden könne?"،72

Die direkte Demokratie als Umfeld machte der Frauenstimmrechtsbewegung in mehrfacher Hinsicht zu schaffen. Einer Ablehnung der Einführung des Frauenstimmrechts durch das „Volk“ war schwer beizukommen. Während sich beispielsweise in England oder in Deutschland politische Proteste gegen eine aristokratische Herrschaft oder gegen eine parlamentarische Mehrheit richteten und damit jeweils eine eindeutige Adressatin hatten, war in der Schweiz kein eigentlicher „Gegner“ auszumachen. Die kontinuierliche Einbindung der oppositionellen Kräfte in die Regierungsverantwortung (man denke nur an die durch das Referendum geförderte Entwicklung der Mehrparteienregierung bis hin zur Proportionalität in der „Zauberformel“ 1959) hatte außerdem zur Folge, dass etablierte Parteien nur wenig Anlass hatten, eine oppositionelle Bewegung wie die Frauenstimmrechtsbewegung zu unterstützen ${ }^{73}$. Gleichzeitig ist festzustellen, dass das ausgeprägte Schweizerische Milizverwaltungssystem auf kommunaler und kantonaler Ebene zur Integration von Frauen beitrug und damit die Dringlichkeit der Forderung nach dem Frauenstimm- und -wahlrecht auf Bundesebene etwas senk$\mathrm{te}^{74}$. Anders ausgedrückt: die direkte Demokratie verpflichtete die Frauenstimmrechtsbewegung auf einen institutionellen, damit aber auch längeren Weg.

71 Vgl. Mesmer, Staatsbürgerinnen (Fn. 54); dies., Ausgeklammert - Eingeklammert: Frauen und Frauenorganisationen in der Schweiz des 19. Jahrhunderts, 1988.

72 Nationalrat Peter von Roten: Begründung des Postulats Nr. 5780 vom 21. Dezember 1949 (vgl. Übersicht der Verhandlungen der Bundesversammlung $1950 \mathrm{~V}$ [Wintersession 1950], S. 22 f. Nr. 85), hier zitiert nach Y. Voegeli, Zwischen Hausrat und Rathaus. Auseinandersetzungen um die politische Gleichberechtigung der Frauen in der Schweiz 1945-1971, 1997, S. 193. Dazu auch der gescheiterte Antrag von Roten vom 23. Juni 1950 zur Wahlrechtsreform, in: Stenographisches Bulletin 60 (1950) Nationalrat, S. 362 ff. und 376.

73 Hardmeier, Frauenstimmrechtskampf (Fn. 39), S. 87.

74 Hardmeier, Frauenstimmrechtskampf (Fn. 39), S. 86. 
Gängige Erklärungsansätze, die sich hauptsächlich auf das politische System der Schweiz berufen, werden durch die in diesem Beitrag analysierten Faktoren nicht in Frage gestellt, sondern ergänzen das Bild um zusätzliche Komponenten.

\section{E. Ein Fazit in Form von Thesen}

Das Frauenstimmrecht ist ein wesentliches, aber keineswegs das einzige Kriterium echter Demokratisierung.

Demokratisierung ist ein langer, langsamer Prozess, der keineswegs geradlinig verlaufen ist: Die Athener Demokratie beruhte ökonomisch auf der Sklaverei und umfasste nur wenige Männer. Dasselbe gilt für die große Mehrzahl der Schweizer Kantone der Alten Eidgenossenschaft.

Noch im 19. Jahrhundert musste sich zuerst eine zensusorientierte Demokratisierung festigen, bevor Erweiterungen möglich wurden.

Demokratisierung in einem breit verstandenen Sinn setzt zumindest in einem überlokalen Kontext Alphabetisierung voraus. Diese geschah in Europa auf breiter Front erst im 19. Jahrhundert. Verschlossene Bildungswege erschwerten es den Frauen zusätzlich, das Mitbestimmungsrecht zu erringen.

Generell ist das Frauenstimmrecht eine sehr späte Blüte am Baum der Demokratisierung. In der Schweiz entwickelte sich das Frauenstimmrecht innerhalb dieser späten Blüte noch einmal retardiert.

Diese Schweizer „Krone der Verspätung“ erklärt sich durch die Demokratisierung selbst ${ }^{75}$ : Nicht eine kleine Elite, sondern die Mehrheit aller über 20jährigen Schweizer Männer war zunächst davon zu überzeugen, dass Demokratie ohne Frauenstimmrecht lediglich Androkratie wäre.

Dass dieser Kampf in der Schweiz spät, aber ohne Gewaltanwendung gewonnen wurde, stellt der Schweizer Demokratie ein gutes Zeugnis aus. Dass die Waffe als Stimmrechtsausweis dabei eine Rolle als Mythentransportmittel spielte, lässt sich freilich kaum bestreiten.

In den parlamentarischen Demokratien mit Zensusorientierung wurde das Wahlrecht im 19. Jahrhundert zunächst für eine verschwindend geringe Anzahl Wahlberechtigter eingeführt: Nach der kaiserlichen Entschließung vom 25. November 1860 über die Zulassung regionaler Wahlen in der Donaumonarchie waren zur ersten demokratischen Wahl der Stadt Wien - zur Feier dieses Ereignisses komponierte Johann Strauss junior für den Ball der Rechtsstudenten seinen Wahlstimmen-Walzer op. 250 - 1861 gerade mal 18.000 Männer unter den rund 550.000 Einwohnern zugelassen; zu den ersten nationalen Parlamentswahlen nach der Auflösung des mittelitalienischen Kirchenstaates waren von über 200.000 Einwohnern Roms ganze 7.144 Männer zugelassen: vgl. G. Seibt, Rom oder Tod. Der Kampf um die italienische Hauptstadt, 2001, S. 204. 
Das Frauenwahlrecht ist eine Forderung, die politisch primär von „links“ kommt. Dies heißt weder, dass sich linke Parteien und Politiker einigermaßen einmütig hinter die Forderungen gestellt hätten, noch dass bürgerliche Parlamentarier generell gegen ein Frauenwahlrecht eingestellt gewesen wären (vgl. z.B. John Stuart Mill). Bürgerliche verfochten zunächst ein Zensuswahlrecht und waren für rechtliche Gleichstellung und Mitentscheidung aller generell entsprechend zögerlich zu haben. Die Erklärung liegt auf der Hand: Sozial Unterschichtige waren bei der industriellen Revolution als erste darauf angewiesen, dass Männer und Frauen (und Kinder!) das tägliche Brot verdienen halfen. Eine arbeitsteilige Gesellschaft, in der die Frauen nicht auf die Hausarbeit beschränkt sind, wirft am raschesten die Frage auf, wieso nicht mitbestimmen soll, wer doch mitverdienen muss ${ }^{76}$.

Auch bei „Linken“ dauerte es lange, bis soziale Frage und Genderproblematik Hand in Hand gingen. Geknechtete Arbeiter hatten dafür weder Zeit noch Sprecher. Erst durch den Einsatz redegewandter Akademiker vermochten sich unterschichtige Forderungen langsam Gehör zu verschaffen.

Das Frauenwahlrecht musste, wie alle demokratischen Rechte „,von unten“, von den Benachteiligten selber, d.h. hier: durch die Frauen erstritten werden. Vielleicht erklärt dies, weshalb (auch) das Frauenwahlrecht nicht von „Superdemokratinnen“ erkämpft wurde. Emmeline Pankhurst und ihre Tochter Christabel Pankhurst gebärdeten sich innerhalb der britischen Suffragettenvereinigung zuweilen wie Diktatoren wenig zimperlich.

Beseitigung der Sklaverei, Emanzipation der Juden und Frauenstimmrecht sind weltweit gleichermaßen sehr späte Errungenschaften der Rechtsgleichheit. Sie beginnen, von geringfügigen lokalen Ausnahmen abgesehen erst ab der zweiten Hälfte des 19. Jahrhunderts n. Chr. und keineswegs in allen Staaten in gleicher Reihenfolge und gleichzeitig. Auffällig am Frauenwahlrecht ist in den meis-

76 M. Karl, „Wir fordern die Hälfte der Welt!“ Der Kampf der Suffragetten um das Frauenstimmrecht, 2009. Die bürgerliche Position prägnant formuliert bei Friedrich Schiller, Demetrius oder Die Bluthochzeit zu Moskau (Fragment zu einem Drama), Erster Aufzug erste Szene (Fürst Leo Sapieha): „... Die Mehrheit?

Was ist die Mehrheit? Mehrheit ist der Unsinn,

Verstand ist stets bei wen'gen nur gewesen.

Bekümmert sich ums Ganze, wer nichts hat?

Hat der Bettler eine Freiheit, eine Wahl?

Er muss dem Mächtigen, der ihn bezahlt,

um Brot und Stiefel seine Stimm verkaufen.

Man soll die Stimmen wägen und nicht zählen;

der Staat muss untergehn, früh oder spät,

wo Mehrheit siegt und Unverstand entscheidet.“

- Die Äußerung sieht der englischen Tory-Position im 19. Jahrhundert inhaltlich zum Verwechseln ähnlich. 
ten Staaten das Entstehen im unmittelbaren Gefolge von Gewaltausbrüchen wie Revolution, Erstreiten der Unabhängigkeit, Bürgerkrieg, Krieg oder Weltkrieg und entsprechender Dezimierung der Männerpopulation. Von derlei Gewaltausbrüchen blieb die Schweiz seit der zweiten Hälfte des 19. Jahrhunderts n. Chr. nahezu völlig verschont. Als einer der wenigen Staaten führten die Männer das Frauenstimmrecht nicht unter dem unmittelbaren Eindruck einer solchen Katastrophe ein. Ist es Zufall, dass bereits in der Antike ein desaströser Krieg einen begabten Satiriker zum Denken in Alternativen brachte: Frauen in der Volksversammlung, und dass der einzige bisher nicht widerlegbare Hinweis auf die eigenverantwortliche Teilnahme von Schweizer Frauen vor der Französischen Revolution die Schwyzer Landsgemeinde nach der verheerenden Niederlage der Eidgenossen in Marignano 1515 betrifft?

Die hier nur paradigmatisch zusammengestellten zeitlichen Relationen zwischen Analphabetismus und Bewaffnungsmythos, Krieg und Frauenwahlrechtsdiskussion, Vorhandensein oder Fehlen zensusorientierter Wahlrechtseinschränkungen und Frauenwahlrechtsentwicklung erscheinen uns merkwürdig. Es wäre eine umfassende historische Untersuchung wert zu eruieren, ob die Erringung des Frauenwahlrechts bei zunehmender „Breite“ der Männerwahlrechts-Demokratie nicht geradezu schwieriger geworden ist. 